\title{
Factors explaining driver yielding behaviour towards pedestrians at courtesy crossings
}

\author{
Paulo Anciaes \\ University College London, United Kingdom \\ Giovanni Di Guardo \\ Transport Planning Associates \\ Peter Jones \\ University College London, United Kingdom
}

Published in Transportation Research Part F: Traffic Psychology and Behaviour 73, 453-469

\begin{abstract}
Courtesy crossings are pedestrian crossing facilities where drivers are not legally required to stop for pedestrians, but are encouraged to do so by design elements such as stripes, coloured or textured road surfaces, visual narrowings of the carriageway, and ramps. There is little empirical evidence on drivers' behaviour and guidance on how to design these crossings. This paper analysed data for 937 interactions between drivers and pedestrians at 20 crossings across England, comparing driver yielding behaviour at courtesy crossings and at zebras (marked unsignalised crossings, where drivers are legally required to stop); and identifying the design elements associated with yielding behaviour at courtesy crossings. The analysis controlled for crossing stage; characteristics and situation of pedestrians and vehicles; characteristics of the road and site; and time of day. Driver yielding behaviour was analysed for each separate traffic lane that pedestrians need to cross. We found that all the four design elements considered (stripes, coloured/textured surface, visual narrowing, and ramps) increased the propensity of the first vehicle to stop and of any vehicle to stop. A before-after analysis then showed that adding a new element (stripes) to a courtesy crossing led to an increase in yielding rates from $20 \%$ to $97 \%$. Overall, we found evidence supporting the use of multiple design elements in courtesy crossings. We discuss the implications of these findings for transport policy and urban design.
\end{abstract}

Keywords: courtesy crossings; driver behaviour; yielding behaviour; driver courtesy; pedestrians; crossing facilities 


\section{Introduction}

The provision of pedestrian crossing facilities is one of the most problematic elements of road planning. Crossing facilities allow for the movement of pedestrians across the road but also generate conflicting movements between pedestrians and motorised vehicles, often becoming hotspots of collisions. Collision risk can be removed by separating vehicles from pedestrians with bridges or underpasses, or simply reduced by controlling movements with traffic signals. However, when the volumes of pedestrians and motorised vehicles are below the level that would justify the costs of signalisation, and traffic speeds are low, marked unsignalised crossings (also known as zebras or marked crosswalks) are often used (DfT 1995, Ch.4.2.3). In most countries, drivers are legally required to give way to pedestrians at these crossings, which are identified by a standardized set of design elements, including white stripes, signs, posts with flashing lights, lighting of the crossing, dotted lines across the carriageway, and zigzag markings on the approach to the crossing (Figure 1).

Figure 1: Example of zebra crossing (marked unsignalised crossing)

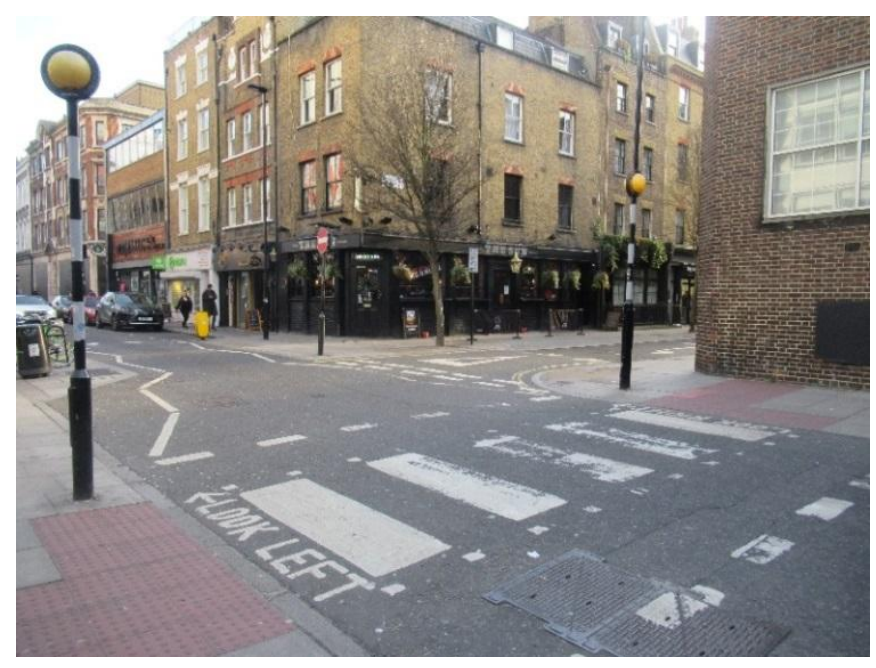

However, there are many instances where pedestrian and vehicle volumes do not meet the minimum criteria even for zebra crossings. These crossings are also relatively expensive to install. In addition, their safety record is often poor (Thulin 2007; Gitelman et al. 2012; Morency et al. 2015), which can be explained by the lack of compliance in yielding by drivers and by pedestrians' unwarranted sense of safety. At the same time, simply removing zebras, without providing any other facilities, may decrease safety even more (Mitman et al. 2008).

For these reasons, it is increasingly common to provide informal 'courtesy crossings', which cost very little to install. At these crossings, drivers are not legally required to give way 
to pedestrians but psychologically encouraged to do so by design elements such as stripes (with no supporting infrastructure, unlike at zebra crossings), coloured or textured surfacing, visual narrowing of the road, and ramps raising the carriageway (Figure 2). For pedestrians, the location of courtesy crossings is identified using elements such as dropped kerbs and colour contrast and/or tactile warnings at the kerbside.

The hypothesis is that the design of courtesy crossings encourages drivers to respond to the presence and behaviour of pedestrians, rather than to formal traffic management elements (such as traffic lights, signs, road markings, or physical separations between kerbs and carriageway). This hypothesis is aligned with the "shared space" design approach, which aims at a more balanced distribution of space by removing formal demarcations between different types of road users, who are expected to become aware of each other. Proponents of this approach argue that it reduces the dominance of motorised vehicles and restores the role of roads and streets as social spaces, while ensuring the safety of pedestrians, as drivers will tend to drive slowly and stop for pedestrians (Hamilton-Baillie 2008a, 2008b).

Figure 2: Examples of elements of courtesy crossings
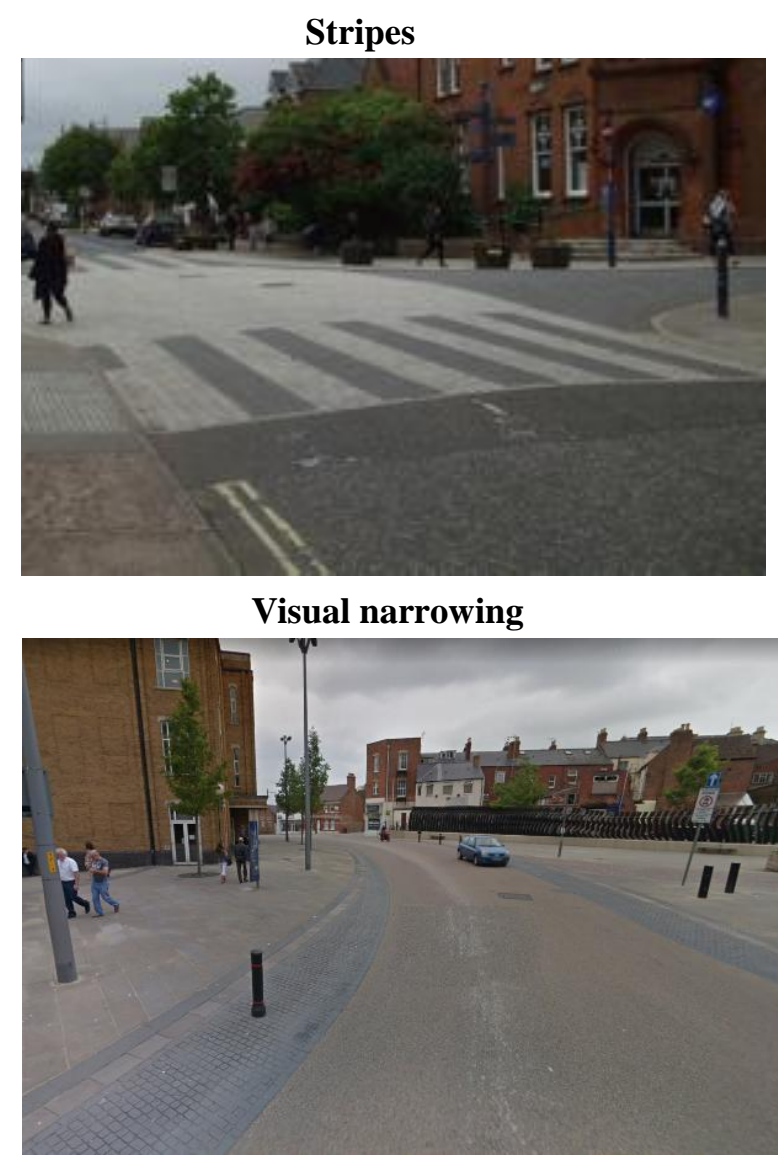

\section{Coloured/textured treatment}

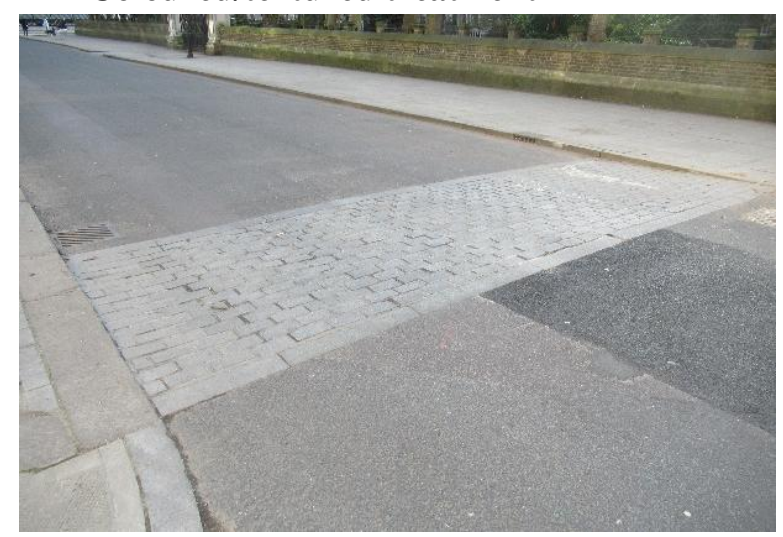

Ramps

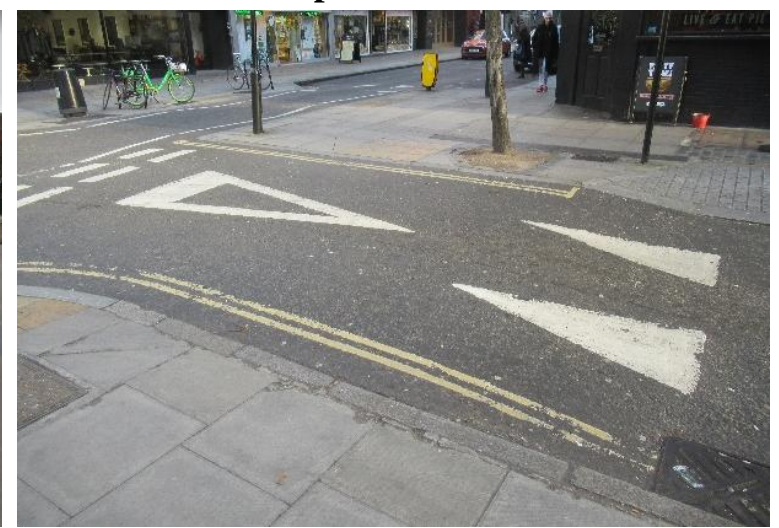

Source: Authors (colour/textured treatment, ramps); CIHT (2018) (stripes and visual narrowing). 
However, providing courtesy crossings has proved to be a controversial practice (Forster 2014), fuelled by reports that both drivers and pedestrians feel confused and are not sure how to behave at these crossings, and that pedestrians would rather have signalised crossings or zebras than courtesy crossings (Moody and Melia 2014). The discussion has been absorbed into the wider debate about the shared space approach. This approach has been criticized because it does not go far enough in reducing the role of motorised vehicles (Methorst 2007) and it does not address the needs of individuals with mobility, visual, or hearing impairments (Hammond and Musselwhite 2013; Havik et al. 2012, 2015; Imrie 2012, 2013).

This controversy has been compounded by the lack of guidance on the provision and design of courtesy crossings, and of a solid empirical base on how these crossings address the movement and safety of pedestrians. In the UK, the Department for Transport's guidance on shared space encouraged courtesy crossings on the grounds that "drivers tend to treat courtesy crossings as they would a zebra crossing" (DfT (2011, p.37). However, the validity of the evidence base of the guidance document has been questioned (Moody and Melia 2014). The recommendations for design elements (tonal contrast, textures, bollards, and raised and narrowed carriageway) were also not based on any evaluation on their effectiveness. The document was withdrawn in 2018, seeking for more research (DfT 2018). In the same year, a guidance document by a professional association suggested that courtesy crossings encourage drivers to "engage with their surroundings rather than simply following traffic rules, which tends to reduce traffic speed" (CIHT 2018, p.22, 25). The document provided evidence on design elements influencing yielding behaviour (speed reduction measures, "conspicuous treatments", locating crossings near junctions, level changes, and median strips) but also recognised the need for more research on how yielding behaviour is related to other characteristics of road design and to the characteristics of pedestrians (CIHT 2018, p.22).

The present paper set out to provide evidence on a crucial aspect of courtesy crossings: the factors that encourage driver yielding behaviour (i.e. drivers stopping to give way to pedestrians). The study was based on the cross-sectional analysis of video data for 937 interactions between drivers and pedestrians at 20 non-signalised crossings across England, and a before-after analysis at one of these crossings, where an additional design element (stripes) was introduced some years after the implementation of the crossing. Our dataset includes both zebra crossings and different types of courtesy crossings, defined by various combinations of design elements (henceforth referred to as "courtesy crossing design elements"). This allowed us to gauge how driver yielding behaviour is related to each 
element, while controlling for the characteristics and situation of pedestrians and vehicles, characteristics of the road and of the site, and time context. The study therefore provides timely empirical evidence addressing the calls made by policy-makers and professional associations and can feed into future guidelines for the provision and design of courtesy crossings.

The next section reviews the existing evidence on courtesy crossings and driver yielding behaviour. Section 3 describes the case studies and the variables collected. Section 4 tests how yielding behaviour varies with the type of crossings and with other factors. Section 5 presents logistic models explaining driver yielding behaviour. Section 6 presents a further logistic model to compare yielding behaviour at one crossing before and after an additional design element was introduced. Section 7 discusses the implications of the results for policy and research.

\section{Existing evidence}

\section{Yielding behaviour at courtesy crossings}

Only a few empirical studies have looked at driver yielding behaviour at courtesy crossings. However, in all cases, the analysis was confounded by the fact the courtesy crossings were integrated into wider shared space schemes. Moody and Melia (2014) found that most pedestrians used a courtesy crossing, rather than the surrounding shared space, effectively treating the courtesy crossing like a zebra crossing. However, drivers did not treat it as such: the yielding rate was just 37\%. In contrast, Horrell and Jones (2014) found that the yielding rate at a courtesy crossing had more than doubled (from $30 \%$ to $62 \%$ ) six months after the opening of a shared space scheme, as drivers and pedestrians became more familiar with the design. In the case studies reviewed by CIHT (2018), yielding rates varied from 5\% to $97 \%$. Overall, these results show a wide variation in the effectiveness of courtesy crossings in encouraging driver yielding behaviour, suggesting that this behaviour depends on either the characteristics of the courtesy crossings or on other crossing-specific factors. More research is therefore needed to isolate these two sets of factors.

\section{Yielding behaviour at marked unsignalised crossings}

The design of this research on courtesy crossings can benefit from information provided by the extensive literature on driver yielding behaviour at marked unsignalised crossings (zebras), which we synthesize in Table 1. Yielding behaviour has been associated with several 
design elements, including crossing width; the existence of a median strip or crossing island; staggered layout; ramps/speed humps; light-based warning systems; kerb extensions; highvisibility signs and markings; advanced yield markings; and on-street signs. The evidence on the effectiveness of light-based warning systems is particularly strong and extensive. However, there is no evidence of the effect of three of the four design elements usually used in courtesy crossings, and analysed in this paper, e.g. (non-zebra) stripes, coloured/textured surface and visual narrowing. There is only one study providing evidence on the fourth design element (ramps).

As shown in Table 1, driver yielding behaviour at zebra crossings is also related to nondesign factors, including the characteristics of pedestrians and vehicles, the situation of both when the interaction occurs, the characteristics of the road (other than the crossing design), the characteristics of the site, and the time of day. The direction of these relationships is not always clear. For example, driver yielding behaviour has been positively and negatively associated to the number of road lanes, the presence of bus stops and of a median strip or crossing island, driving in queues/platoons, and driving in the nearside lane (closer to the kerb where the pedestrian is waiting). Some results also go against prior expectations. For example, Porter et al. (2016) found that drivers were 1.83 times more likely to stop for pedestrians when they were still on the pavement than when they had already started crossing. Another limitation of the literature is the bias towards case studies in the USA (62\% of the studies in Table 1), producing results that may not apply in other parts of the world, which have different traffic regulations and tend to have a higher proportion of pedestrians in the total traffic. 
Table 1: Factors explaining driver yielding behaviour at marked unsignalised crossings (zebras)

\begin{tabular}{|c|c|c|}
\hline $\begin{array}{l}\text { Factor associated with } \\
\text { yielding behaviour }\end{array}$ & $\begin{array}{l}\text { Sign of the } \\
\text { association }\end{array}$ & Studies \\
\hline \multicolumn{3}{|l|}{ Crossing design elements } \\
\hline Crossing width & + & Stapleton et al. 2017 \\
\hline \multirow[t]{2}{*}{ Median strip/crossing island } & + & Pulugurtha et al. 2012 \\
\hline & - & Porter et al. 2016, Stapleton et al. 2017 \\
\hline $\begin{array}{l}\text { Staggered crossing ('Danish } \\
\text { offset') }\end{array}$ & + & Pulugurtha et al. 2012 \\
\hline Ramps/speed humps & + & Gitelman et al. 2017b \\
\hline Light-based warning systems & + & $\begin{array}{l}\text { Schroeder and Rouphail 2011, Foster et al. 2014, Porter et al. } \\
\text { 2016, Al-Kaisy et al. 2017, Stapleton et al. 2017, Høye and } \\
\text { Laureshyn } 2019\end{array}$ \\
\hline Kerb extensions & + & Bella and Silvestri 2015 \\
\hline High-visibility signs and markings & & $\begin{array}{l}\text { Pulugurtha et al. 2012, Fisher and Garay-Vega 2012, Sandt et } \\
\text { al. } 2016\end{array}$ \\
\hline Advanced yield markings & + & Fisher and Garay-Vega 2012, Bella and Silvestri 2015 \\
\hline In-street signs & + & $\begin{array}{l}\text { Strong and Ye 2010, Schroeder and Rouphail 2011, Bennett et } \\
\text { al. 2014, Stapleton et al. } 2017\end{array}$ \\
\hline \multicolumn{3}{|l|}{ Pedestrian characteristics } \\
\hline Presence of children & + & Al-Kaisy et al. 2017, Sucha et al. 2017 \\
\hline Presence of elderly & + & Al-Kaisy et al. 2017 \\
\hline Same age group as driver & + & Rosenbloom et al. 2006 \\
\hline Disability & + & Harrell 1992, Geruschat and Hassan 2005 \\
\hline Ethnic minority & & $\begin{array}{l}\text { Goddard et al. 2015, Schneider et al. 2018, Coughenour et al. } \\
2017\end{array}$ \\
\hline \multicolumn{3}{|r|}{ Stror } \\
\hline Number of pedestrians & + & $\begin{array}{l}\text { Figliozzi and Tipagornwong 2016, Sucha et al. 2017, Al-Kaisy } \\
\text { et al. 2017, Malenje } \text { et al. 2019, Obeid et al. } 2017\end{array}$ \\
\hline Conspicuity /Assertive behaviour & + & $\begin{array}{l}\text { Harrell 1993, Schroeder and Rouphail 2011, Schneider et al. } \\
2018\end{array}$ \\
\hline Distracted behaviour & - & Sucha et al. 2017 \\
\hline Friendliness & + & Guéguen et al. 2016 \\
\hline Waiting away from kerb & - & Al-Kaisy et al. 2017, Sucha et al. 2017 \\
\hline Already crossing (not waiting) & & Gorrini et al. 2018 \\
\hline & & Porter et al. 2016 \\
\hline $\begin{array}{l}\text { Crossing from opposite pavement } \\
\text { (not nearside) }\end{array}$ & + & Gorrini et al. 2018 \\
\hline $\begin{array}{l}\text { Second stage of crossing (at a } \\
\text { staggered crossing) }\end{array}$ & + & Foster et al. 2014 \\
\hline \multicolumn{3}{|l|}{ Vehicle characteristics } \\
\hline Cars & + & Porter et al. 2016, Figliozzi and Tipagornwong 2016 \\
\hline Buses & + & Craig et al. 2019b \\
\hline \multicolumn{3}{|l|}{ Vehicle situation } \\
\hline Traffic density & - & Sucha et al. 2017 \\
\hline Speed & - & Geruschat and Hassan 005, Sucha et al. 2017 \\
\hline $\begin{array}{l}\text { Change in speed (up or down) } \\
\text { before approaching crossing }\end{array}$ & - & Figliozzi and Tipagornwong 2016 \\
\hline $\begin{array}{l}\text { Vehicle had stopped at traffic } \\
\text { lights before approaching crossing }\end{array}$ & + & Figliozzi and Tipagornwong 2016 \\
\hline \multirow[t]{2}{*}{ Travelling in queues/platoons } & + & Sucha et al. 2017 \\
\hline & & Schroeder and Rouphail 2011 \\
\hline \multirow[t]{2}{*}{ In nearside lane (closer to kerb) } & & Schroeder and Rouphail 2011 \\
\hline & - & Stapleton et al. 2017 \\
\hline $\begin{array}{l}\text { Another vehicle yield in adjacent } \\
\text { lane }\end{array}$ & + & $\begin{array}{l}\text { Schroeder and Rouphail 2011, Figliozzi and Tipagornwong } \\
2016\end{array}$ \\
\hline
\end{tabular}




\begin{tabular}{lll}
\hline Road characteristics & & \\
Junction (not link) & + & Sandt et al. 2016 \\
Road width/crossing distance & - & Schneider et al. 2018 \\
Number of lanes & + & Craig et al. 2019a \\
& - & Sandt et al. 2016, Malenje et al. 2019 \\
Traffic levels & - & Schneider et al. 2018 \\
Speed limits & - & Sandt et al. 2016, Schneider et al. 2018 \\
Kerbside parking & - & Obeid et al. 2017 \\
\hline Site characteristics & & \\
Bus stop & + & Schneider et al. 2018 \\
City population & - & Craig et al. 2019b \\
Time & - & Sandt et al. 2016 \\
Morning (vs. afternoon) & & \\
\hline
\end{tabular}

Also relevant are studies comparing driver behaviour at marked unsignalised crossings (zebras) and unmarked crossing points (not in Table 1). Most studies (e.g. Mitman et al. 2008, Havard and Willis 2012, Obeid et al. 2017, Gitelman et al 2017a, Craig et al. 2019a) found that drivers were more likely to yield at marked crossings. However, Knoblauch et al. (2001) found no significant differences in yielding behaviour at marked and unmarked crossings. Again, the evidence base is small, as most of the research on the topic has focused on pedestrian behaviour, not on driver behaviour.

\section{Yielding behaviour in shared spaces}

Additional information could be provided by the literature on interactions between users of shared spaces. However, most of this literature is either thought pieces or evaluation studies of specific shared space schemes, not providing a comparative assessment of the effect of different design elements on driver behaviour. An exception is the study of MVA (2010), which showed that the propensity of drivers to give way to pedestrians was related to the number of pedestrians, the number of vehicles behind or in front, lack of kerbs, less definition between surface colours, presence of traffic calming measures, and an index of how "shared" the space is. Using surveys, Kaparias et al. (2012) found that drivers are less willing to share space when using larger vehicles and in spaces with street furniture, without bright lighting, and used by many vehicles and pedestrians (especially children and older adults). The authors interpreted these as factors increasing drivers' uneasiness, and thus their alertness, when using shared spaces, which may then affect the propensity to stop or drive slowly.

\section{Unanswered questions and the contribution of this paper}

Despite providing a useful list of factors explaining driver yielding behaviour, the results of the literatures on marked unsignalised crossings (zebras) and on shared spaces do not fully 
apply to courtesy crossings. In most countries, the design elements of zebras are relatively fixed and there is a legal requirement for drivers to stop. In contrast, the design of courtesy crossings is flexible, and planners can combine different elements in the hope that they will persuade drivers to stop, even though there is no legal requirement to do so. In shared spaces, driver yielding behaviour refers both to pedestrians walking along and across the road; and pedestrians can, in theory, cross anywhere. In contrast, courtesy crossings are designated places where pedestrians move across the road and their location is identified both to pedestrians and to drivers.

The current paper therefore aims at covering the gap left by the literatures on marked unsignalised crossings and shared spaces, investigating the role of the courtesy crossing design elements, while controlling for the non-design factors identified in those two literatures.

\section{Data and variables}

\section{Crossings}

The study analysed 20 crossings at 12 sites in urban areas in England. Some sites are junctions and others are links. Sites that are junctions have more than one crossing, on different arms of the junction. Table 2 shows the main characteristics of the crossings. The figure in the appendix to the paper shows detailed illustrations of the layouts of the crossings. The set of crossings includes 3 marked unsignalised crossings (zebras) and 17 courtesy crossings with different combinations of four courtesy crossing design elements: stripes, colour/texture treatment, visual narrowing, and ramps. This allowed us to assess the influence of each design element on driver yielding behaviour. The crossings also had a variety of different infrastructure characteristics (total number of lanes and presence vs. absence of a median strip) and traffic regulations (one-way vs. two-way traffic).

Video surveys were conducted at all crossings between August 2014 and July 2015. In

Crossing 8, the survey was conducted in 2009. In Crossing 7, two surveys were conducted, in August 2014 and February 2015, before and after the characteristics of the crossing changed, with the introduction of (non-zebra) stripes. The duration of the survey was 14-18 minutes in Crossings 8, 11B, 11C, and 7 (in 2015) and around 30 minutes in all other crossings. Some surveys were conducted on weekdays, others on a Saturday, at different times of day. In four crossings, the exact time of day is unknown. In the analysis that follows, dummy variables 
were created for surveys on Saturdays, weekdays, peak-time (defined as the 6:30-10:00 and 16:30-20:00 periods), not peak-time, and an unknown time of day.

The number of motorised vehicles traversing the road per minute ranged from 3.3 to 15.5 and the total number of pedestrians per minute ranged from 0.4 to 13.6. These numbers are relatively low, which is consistent with the requirements of zebras and courtesy crossings. There were different combinations of volumes of vehicles and pedestrians. Some crossings had more than 20 times more vehicles than pedestrians, but others had a balanced number of pedestrians and vehicles or even more pedestrians than vehicles. The total number of pedestrians tracked across all crossings was 2476.

A series of crossing-specific variables was also collected from the video footage, measuring:

- Road characteristics: location (on a junction with inbound traffic, junction with outbound traffic, or link, i.e. away from junction); speed limit (20mph or $30 \mathrm{mph}$ ); and whether the kerb was raised or not. Raised kerbs are relevant because they are formal demarcations between vehicles and pedestrians and may influence drivers' yielding behaviour.

- Site characteristics: whether there were shops and services along the footway or not. 
Table 2: Crossings included in the study

\begin{tabular}{|c|c|c|c|c|c|c|c|c|c|c|c|c|c|c|c|}
\hline \multirow[b]{2}{*}{$\begin{array}{l}\text { Crossing } \\
\text { ID }\end{array}$} & \multirow[b]{2}{*}{ Site } & \multirow[b]{2}{*}{$\begin{array}{c}\text { Total } \\
\text { number } \\
\text { of lanes }\end{array}$} & \multirow[b]{2}{*}{$\begin{array}{c}\text { One- } \\
\text { way } \\
\text { traffic }\end{array}$} & \multirow[b]{2}{*}{$\begin{array}{c}\text { Median } \\
\text { strip }\end{array}$} & \multirow[b]{2}{*}{ Zebra } & \multicolumn{4}{|c|}{ Courtesy crossing design elements } & \multicolumn{3}{|c|}{ Video } & \multicolumn{3}{|c|}{ Traffic } \\
\hline & & & & & & $\begin{array}{c}\text { Stripes } \\
\text { (not } \\
\text { zebra) }\end{array}$ & $\begin{array}{c}\text { Colour/ } \\
\text { texture } \\
\text { treatment }\end{array}$ & $\begin{array}{l}\text { Visual } \\
\text { narrowing }\end{array}$ & Ramps & $\begin{array}{l}\text { Day of } \\
\text { week }\end{array}$ & $\begin{array}{l}\text { Time } \\
\text { of day }\end{array}$ & $\begin{array}{l}\text { Duration } \\
\text { (minutes) }\end{array}$ & $\begin{array}{c}\text { Number of } \\
\text { vehicles } \\
\text { per minute }\end{array}$ & $\begin{array}{l}\text { Number of } \\
\text { pedestrians } n \\
\text { per minute } p\end{array}$ & $\begin{array}{c}\text { Total } \\
\text { number of } \\
\text { eedestrians }\end{array}$ \\
\hline $1 \mathrm{~A}$ & \multirow{2}{*}{ Arnsberg Way, Bexleyheath } & 2 & & & & $\mathrm{x}$ & $\mathrm{x}$ & & $\mathrm{x}$ & \multirow{2}{*}{ Saturday } & $11: 08$ & 32 & 10.9 & 1.8 & 57 \\
\hline $1 \mathrm{~B}$ & & 2 & & $\mathrm{x}$ & & $\mathrm{x}$ & $\mathrm{x}$ & & $\mathrm{x}$ & & $11: 38$ & 30 & 7.6 & 3.1 & 92 \\
\hline 2 & Albion Road, Bexleyheath & 3 & & $\mathrm{x}$ & & $\mathrm{x}$ & & & $\mathrm{x}$ & Saturday & $14: 16$ & 30 & 10.7 & 7.7 & 230 \\
\hline 3 & Promenade, Blackpool & 2 & & & $\mathrm{x}$ & & & & & Tuesday & N/A & 28 & 15.5 & 7.5 & 216 \\
\hline 4 & $\begin{array}{l}\text { Shenley Road, } \\
\text { Borehamwood }\end{array}$ & 2 & & $\mathrm{x}$ & & & & & $\mathrm{x}$ & Friday & $17: 20$ & 26 & 10.9 & 3.3 & 86 \\
\hline $5 \mathrm{~A}$ & \multirow{2}{*}{ Gosford Street, Coventry } & 2 & & & & & $\mathrm{x}$ & & & \multirow{2}{*}{ Thursday } & $14: 54$ & 32 & 6.7 & 3.0 & 98 \\
\hline $5 \mathrm{~B}$ & & 2 & & & & & $\mathrm{x}$ & & & & $14: 54$ & 32 & 5.4 & 1.7 & 54 \\
\hline 6 & Hamilton Road, Felixstowe & 2 & & & & $\mathrm{x}$ & $\mathrm{x}$ & & $(\mathrm{x})$ & Wednesday & $10: 21$ & 25 & 3.3 & 9.5 & 239 \\
\hline $7_{(2014)}$ & \multirow{2}{*}{$\begin{array}{l}\text { Kimbrose Triangle, } \\
\text { Gloucester }\end{array}$} & 2 & & & & \multirow{2}{*}{\multicolumn{2}{|c|}{$\mathrm{x}$}} & $\mathrm{x}$ & & \multirow{2}{*}{$\begin{array}{l}\text { Wednesday } \\
\text { Tuesday }\end{array}$} & $11: 01$ & 30 & 13.3 & 7.8 & 233 \\
\hline $7_{(2015)}$ & & 2 & & & & & & $\mathrm{x}$ & & & N/A & 18 & 11.5 & 11.3 & 204 \\
\hline 8 & $\begin{array}{l}\text { King Edward Road, } \\
\text { Knutsford }\end{array}$ & 3 & & $\mathrm{x}$ & $\mathrm{x}$ & & & & & Friday & N/A & 15 & 11.7 & 13.6 & 206 \\
\hline $9 \mathrm{~A}$ & \multirow{2}{*}{ Fountain Place, Poynton } & 2 & & & & & $\mathrm{x}$ & $\mathrm{x}$ & $(\mathrm{x})$ & \multirow{2}{*}{ Friday } & $16: 00$ & 25 & 15.1 & 0.9 & 23 \\
\hline $9 \mathrm{~B}$ & & 2 & & & & & $\mathrm{x}$ & $\mathrm{x}$ & & & $14: 49$ & 29 & 15 & 1.5 & 43 \\
\hline $10 \mathrm{~A}$ & \multirow{2}{*}{ Park Lane, Poynton } & 2 & & & & & $\mathrm{x}$ & $\mathrm{x}$ & $\mathrm{x}$ & \multirow{2}{*}{ Friday } & $15: 26$ & 27 & 13.7 & 1.1 & 30 \\
\hline $10 \mathrm{~B}$ & & 2 & & & & & $\mathrm{x}$ & $\mathrm{x}$ & $\mathrm{x}$ & & N/A & 25 & 10.9 & 0.4 & 10 \\
\hline $11 \mathrm{~A}$ & \multirow{3}{*}{ Fishergate, Preston } & 1 & $\mathrm{x}$ & & & & $\mathrm{x}$ & $\mathrm{x}$ & & \multirow{3}{*}{ Wednesday } & $11: 15$ & 28 & 7 & 4.5 & 129 \\
\hline $11 \mathrm{~B}$ & & 1 & $\mathrm{x}$ & & & & $\mathrm{x}$ & $\mathrm{x}$ & & & $10: 26$ & 17 & 6.5 & 2.5 & 43 \\
\hline $11 \mathrm{C}$ & & 1 & $\mathrm{x}$ & & $\mathrm{x}$ & & & & & & $10: 54$ & 14 & 1.6 & 4.8 & 68 \\
\hline $12 \mathrm{~A}$ & \multirow{3}{*}{ Regent Circus, Swindon } & 2 & $\mathrm{x}$ & & & & $\mathrm{x}$ & & $\mathrm{x}$ & \multirow{3}{*}{ Tuesday } & $09: 12$ & 30 & 8.1 & 5.0 & 150 \\
\hline $12 \mathrm{~B}$ & & 1 & $\mathrm{x}$ & & & & $\mathrm{x}$ & & $\mathrm{x}$ & & $09: 12$ & 30 & 5.3 & 3.5 & 104 \\
\hline $12 \mathrm{C}$ & & 1 & $\mathrm{x}$ & & & & $\mathrm{x}$ & & $\mathrm{x}$ & & 09:12 & 30 & 9 & 5.4 & 161 \\
\hline All & & & & & & & & & & & & & 9.6 & 4.4 & 2476 \\
\hline
\end{tabular}

Notes: In Crossings 6 and 9A, ramps were present in one direction only. Exact time of day is unknown in crossings 3, $7_{(2015)}, 8$, and $10 \mathrm{~B}$. 


\section{Crossing stages}

We consider that a separate interaction between pedestrians and drivers may occur at each crossing stage, defined as each road lane that pedestrians need to cross. We distinguished between crossing from and to the footway and crossing from or to the median strip, when the road has one; and between the first and the second lane on the way from/to the footway or median strip. This provides extra detail to the analysis of driver yielding behaviour, which, in the majority of studies (including those in Table 1), analyse a single vehicle-pedestrian interaction per pedestrian. Almodfer et al. (2016) and Zhang et al. (2017) studied lane-based vehicle-pedestrian interactions, but focused on busy roads with marked unsignalised crossings (not courtesy crossings) and assessed interactions in terms of proximity between drivers and pedestrians (not driver yielding behaviour).

The left side of Table 3 (all columns except the last three) shows how crossing stages were defined, for all combinations of infrastructure characteristics (presence of median strip and total number of lanes for motorised traffic) and traffic regulations (1-way or 2-way traffic):

- If the road had no median strip and 1 lane, there was just one stage: from footway to footway.

- If the road had no median strip and two lanes, there were two stages: the first and the second lane. We distinguished the case when the road has one-way traffic (i.e. both lanes have traffic in the same direction) and two-way traffic (i.e. the second lane has traffic in the opposite direction of the first lane).

- If the road had a median strip and two lanes, there are two crossing stages: from the footway to the median and from the median to the footway.

- If the road had a median strip and three lanes, there are three crossing stages: the first lane from the footway, the first lane from the median, and the second lane (either on the way from the footway to the median or from the median to the footway).

In the analysis that follows, two dummy variables were created for crossing stages from the median and to the median (regardless of the lane number). The omitted category is "from footway to footway". Another two dummy variables were created for the second lane and second lane with traffic in the opposite direction (regardless of whether it is from or to the median or from footway to footway). The omitted category is the first lane.

We did consider crossing direction. As an example, in a road aligned from West to East, crossing from the North to the South footway was captured in the same variable ("from footway to footway") as crossing from the South to the North footway. 
Table 3: Road characteristics, crossing stages, and events

\begin{tabular}{|c|c|c|c|c|c|c|c|c|c|}
\hline 荧 & 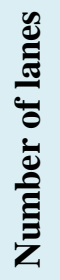 & 窇 & 壳 & 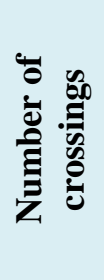 & 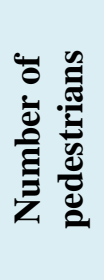 & $\begin{array}{l}\text { Crossing } \\
\text { stage }\end{array}$ & $\begin{array}{l}\text { Number } \\
\text { of events }\end{array}$ & $\begin{array}{l}\text { Number of } \\
\text { events with } \\
\text { interaction }\end{array}$ & $\begin{array}{l}\text { Interaction } \\
\text { rate }\end{array}$ \\
\hline \multirow{5}{*}{ No } & 1 & 1-way & 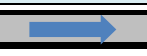 & 1 & 505 & Footway $\rightarrow$ Footway & 302 & 105 & $35 \%$ \\
\hline & \multirow{4}{*}{2} & \multirow{2}{*}{ 1-way } & & \multirow{2}{*}{5} & \multirow{2}{*}{150} & $\begin{array}{c}\text { Footway } \rightarrow \text { Footway } \\
\text { Lane } 1 \\
\end{array}$ & 94 & 36 & $38 \%$ \\
\hline & & & $\Rightarrow$ & & & $\begin{array}{c}\text { Footway } \rightarrow \text { Footway } \\
\text { Lane } 2\end{array}$ & 94 & 11 & $12 \%$ \\
\hline & & \multirow{2}{*}{ 2-way } & & \multirow{2}{*}{10} & \multirow{2}{*}{1207} & $\begin{array}{c}\text { Footway } \rightarrow \text { Footway } \\
\text { Lane } 1\end{array}$ & 639 & 292 & $46 \%$ \\
\hline & & & $\Rightarrow$ & & & $\begin{array}{c}\text { Footway } \rightarrow \text { Footway } \\
\text { Lane } 2 \text { (opposite) }\end{array}$ & 639 & 276 & $43 \%$ \\
\hline \multirow{6}{*}{ Yes } & \multirow{2}{*}{2} & \multirow{2}{*}{ 2-way } & 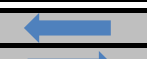 & \multirow{2}{*}{2} & \multirow{2}{*}{178} & Footway $\rightarrow$ Median & 65 & 30 & $46 \%$ \\
\hline & & & $\Rightarrow$ & & & Median $\rightarrow$ Footway & 65 & 31 & $48 \%$ \\
\hline & \multirow{4}{*}{3} & \multirow{4}{*}{ 2-way } & & \multirow{4}{*}{2} & \multirow{4}{*}{436} & $\begin{array}{c}\text { Footway } \rightarrow \text { Median } \\
\text { Lane } 1\end{array}$ & 102 & 76 & $75 \%$ \\
\hline & & & 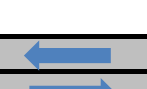 & & & $\begin{array}{c}\text { Footway } \rightarrow \text { Median } \\
\text { Lane } 2\end{array}$ & 20 & 5 & $25 \%$ \\
\hline & & & $\Rightarrow$ & & & $\begin{array}{c}\text { Median } \rightarrow \text { Footway } \\
\text { Lane } 1\end{array}$ & 102 & 51 & $50 \%$ \\
\hline & & & & & & $\begin{array}{c}\text { Median } \rightarrow \text { Footway } \\
\text { Lane } 2 \\
\end{array}$ & 82 & 24 & $29 \%$ \\
\hline All & & & & 20 & 2476 & & 2204 & 937 & $43 \%$ \\
\hline
\end{tabular}

\section{Events and interactions}

We defined an event as the presence of a pedestrian or group of pedestrians starting a crossing stage, i.e. attempting to cross a road lane. Table 3 above shows the number of events by crossing stage for each type of crossing. There were 2204 events across all crossings during the survey periods. The total number of events is smaller than the number of pedestrians because in many events pedestrians crossed as a group.

We considered that there was interaction in an event if the pedestrian(s) crossed and at least one vehicle was approaching, and therefore the driver had to make the decision to give way or not. No interaction was the case when the pedestrian(s) crossed the road with no approaching vehicles or between already stationary vehicles. Across all crossings, there was interaction in 937 events - an interaction rate of 43\%. As shown in Table 3, the interaction rate was always lower in the second lane of traffic moving in the same direction, compared with the first lane. Events where there was no interaction were excluded from further analysis. 
We then recorded, for each event with interaction, whether the first vehicle approaching the crossing, and whether any vehicle (the first or any of the subsequent vehicles), gave way to pedestrians.

A series of variables specific to each event was also collected, including:

- Pedestrian situation: number of pedestrians crossing together (transformed into dummy variables for "single pedestrian" and "group", i.e. more than one pedestrian") and whether there was another pedestrian or group of pedestrians crossing ahead or crossing from the other side.

- Pedestrian characteristics: sex (male/female), approximate age (child: younger than 12; younger adult (aged 12-70) and older adult (aged above 70), and presence of mobility restrictions (wheelchair or walking stick user; and pedestrians walking with a pram (baby carriage), luggage, or dogs).

- Vehicle situation: whether the vehicle was followed by another one or not.

- Vehicle characteristics: larger vehicle (Heavy Goods Vehicle or bus) vs. small vehicle (car or motorcycle).

The classification of the situations and characteristics listed above was done by a single assessor. The classification was straightforward in almost all cases. While there is always an unavoidable degree of subjectivity and uncertainty in the classification of sex and age of pedestrians, in this study, the quality of the footage was good enough to minimize this issue.

\section{Yielding rates}

The first vehicle yielded to pedestrians in $72.8 \%$ of all events and at least one vehicle yielded in $80.9 \%$ of all events in all crossings. Among the three zebra crossings, these proportions were $88.0 \%$ and $96.4 \%$ and among the 20 courtesy crossings, they were $68.9 \%$ and $76.9 \%$, respectively. Table 4 shows yielding rates disaggregated by type of crossing, defined by whether the crossing is a zebra crossing or a courtesy crossing, and if the latter, by combinations of courtesy crossings design elements. The table also shows the number of crossings and events for each type of crossing. The table is sorted in ascending order of the yielding rates of the first vehicle.

Two courtesy crossings had higher yielding rates than the set of zebra crossings. These were the crossing with (non-zebra) stripes and visual narrowing (first vehicle stopped in 
$96.9 \%$ of events and at least one vehicle stopped in $99.4 \%$ of events) and the crossing with stripes and colour/texture treatment ( $94.7 \%$ in both cases).

The table also shows a wide variation in yielding rates by type of crossing. For most types of crossings, the rates were above $50 \%$. In contrast, the set of two courtesy crossings that have colour treatment as the only courtesy crossing design element had very low yielding rates of only $4.3 \%$ and the courtesy crossing with visual narrowing as the single design element had courtesy rates of $20.2 \%$ (first vehicle stops) and $41.6 \%$ (any vehicle stops).

Table 4: Yielding rates per type of crossing

\begin{tabular}{|c|c|c|c|c|c|c|c|c|}
\hline \multirow[b]{2}{*}{ Zebra } & \multicolumn{4}{|c|}{$\begin{array}{c}\text { Courtesy crossing } \\
\text { design elements }\end{array}$} & \multirow{2}{*}{$\begin{array}{l}\text { Number } \\
\text { of } \\
\text { crossings }\end{array}$} & \multirow{2}{*}{$\begin{array}{l}\text { Number } \\
\text { of events }\end{array}$} & \multirow{2}{*}{$\begin{array}{c}\% \text { events } \\
\text { where first } \\
\text { vehicle stops }\end{array}$} & \multirow{2}{*}{$\begin{array}{c}\% \text { events } \\
\text { where any } \\
\text { vehicle stops }\end{array}$} \\
\hline & $\begin{array}{c}\text { Stripes } \\
\text { (not } \\
\text { zebra) }\end{array}$ & $\begin{array}{c}\text { Colour/ } \\
\text { texture } \\
\text { treatment }\end{array}$ & $\begin{array}{c}\text { Visual } \\
\text { narrowing }\end{array}$ & Ramps & & & & \\
\hline & & $\mathrm{X}$ & & & 2 & 47 & 4.3 & 4.3 \\
\hline & & & $\mathrm{X}$ & & 1 & 89 & 20.2 & 41.6 \\
\hline & & $\mathrm{x}$ & $\mathrm{x}$ & & 4 & 41 & 53.7 & 53.7 \\
\hline & & $\mathrm{x}$ & $\mathrm{x}$ & $\mathrm{x}$ & 3 & 27 & 66.7 & 77.8 \\
\hline & & & & $\mathrm{x}$ & 1 & 37 & 75.7 & 91.9 \\
\hline & & $\mathrm{x}$ & & $\mathrm{x}$ & 3 & 129 & 76 & 83.7 \\
\hline & $\mathrm{x}$ & $\mathrm{x}$ & & $\mathrm{x}$ & 4 & 193 & 78.2 & 87.6 \\
\hline \multirow[t]{3}{*}{$\mathrm{X}$} & & & & & 3 & 192 & 88.0 & 96.4 \\
\hline & $\mathrm{x}$ & $\mathrm{x}$ & & & 1 & 19 & 94.7 & 94.7 \\
\hline & $\mathrm{X}$ & & $\mathrm{X}$ & & 1 & 163 & 96.9 & 99.4 \\
\hline \multicolumn{5}{|c|}{ Whole sample } & 23 & 937 & 72.8 & 80.9 \\
\hline
\end{tabular}

Notes: Differences in the sample significant using chi-square test $(\mathrm{p}<0.001)$. Total number of crossing adds to 23 because Crossing 7 had different characteristics at two moments in time and Crossings 6 and 9A had different characteristics per traffic direction (see note to Table 2).

Table 5 shows the yielding rates in the sets of all 3 zebra crossings and all 20 courtesy crossings disaggregated by segments of the sample. These segments were defined by crossing stage, pedestrian and vehicle situation and characteristics, road and site characteristics, and time context. The table also shows (in the columns labelled "n") the frequency of each segment in the whole sample and in zebras and courtesy crossings separately. Differences in yielding rates in different segments were tested using a Chi-square test of proportions. The differences that were significant at least at the $10 \%$ level are marked in the table. 


\begin{tabular}{|c|c|c|c|c|c|c|c|c|c|c|c|}
\hline \multirow{3}{*}{ Variable } & \multirow{3}{*}{$\mathbf{n}$} & \multicolumn{5}{|c|}{ Zebras } & \multicolumn{5}{|c|}{ Courtesy crossings } \\
\hline & & \multirow[t]{2}{*}{$\mathbf{n}$} & \multicolumn{2}{|c|}{$\begin{array}{l}\text { First vehicle } \\
\text { stops }(\%)\end{array}$} & \multicolumn{2}{|c|}{$\begin{array}{l}\text { Any vehicle } \\
\text { stops }(\%)\end{array}$} & \multirow[t]{2}{*}{$\mathbf{n}$} & \multicolumn{2}{|c|}{$\begin{array}{l}\text { First vehicle } \\
\text { stops }(\%)\end{array}$} & \multicolumn{2}{|c|}{$\begin{array}{c}\text { Any vehicle } \\
\text { stops (\%) }\end{array}$} \\
\hline & & & $\%$ & p & $\%$ & p & & $\%$ & p & $\%$ & p \\
\hline \multicolumn{12}{|l|}{ Crossing stage } \\
\hline From median strip to footway & 111 & 31 & 80.7 & \multirow{3}{*}{$<0.001$} & 90.3 & \multirow{3}{*}{0.013} & 80 & 80.0 & \multirow{3}{*}{0.006} & 90.0 & \multirow{3}{*}{$<0.001$} \\
\hline From footway to median strip & 106 & 34 & 67.7 & & 91.2 & & 72 & 79.2 & & 88.9 & \\
\hline From footway to footway & 720 & 127 & 95.3 & & 99.2 & & 593 & 66.1 & & 73.7 & \\
\hline First Lane & 621 & 113 & 82.3 & \multirow{3}{*}{0.002} & 95.6 & \multirow{3}{*}{$\underset{*}{0.069}$} & 508 & 69.5 & & 78.0 & \multirow{3}{*}{0.199} \\
\hline Second Lane & 40 & 18 & 83.3 & & 88.9 & & 22 & 91.7 & 0.149 & 91.7 & \\
\hline Second Lane (opposite direction) & 276 & 61 & 100 & & 100 & & 215 & 66.1 & & 73.5 & \\
\hline Pedestrian situation & & & & & & & & & & & \\
\hline Single pedestrian & 430 & 28 & 78.6 & 0.096 & 92.9 & (0) 285 & 402 & 66.9 & (0) 215 & 74.6 & 100 \\
\hline Group & 507 & 164 & 89.6 & & 97.0 & 0.285 & 343 & 71.1 & 0.215 & 79.6 & 0.109 \\
\hline No others & 743 & 168 & 86.9 & & 96.4 & & 575 & 64.0 & & 73.6 & \\
\hline Others crossing ahead & 101 & 24 & 95.8 & 0208 & 95.8 & 0884 & 77 & 84.4 & $<0.001$ & 87.0 & 0.001 \\
\hline $\begin{array}{l}\text { Others crossing from opposite } \\
\text { side }\end{array}$ & 85 & 0 & & & 96.3 & & 85 & 84.7 & & 88.2 & \\
\hline Pedestrian characteristics & & & & & & & & & & & \\
\hline Female $>0$ & 569 & 141 & 92.2 & 0.003 & 97.2 & 0320 & 428 & 69.6 & 0500 & 79.0 & 0121 \\
\hline Female $=0$ & 368 & 51 & 76.5 & & 94.1 & 0.320 & 317 & 67.8 & 0.599 & 74.1 & 0.121 \\
\hline Child $>0$ & 124 & 52 & 96.2 & 0.034 & 100 & 0.099 & 72 & 66.7 & 0672 & 81.9 & 0286 \\
\hline Child $=0$ & 813 & 140 & 85.0 & & 95.0 & & 673 & 69.1 & $0.0 / 3$ & 76.4 & 0.286 \\
\hline Adult (older) $>0$ & 97 & 22 & 95.5 & ( 254 & 100.0 & 0322 & 75 & 58.7 & 0.044 & 72.0 & 0287 \\
\hline Adult (older) $=0$ & 840 & 170 & 87.1 & .254 & 95.9 & 0.332 & 670 & 70.0 & & 77.5 & 0.281 \\
\hline No mobility restrictions & 835 & 169 & 88.8 & & 96.5 & & 666 & 69.7 & & 76.7 & \\
\hline With pram/bags/luggage/dogs $>0$ & 79 & 21 & 81.0 & 0.301 & 95.2 & 0.781 & 58 & 65.5 & 0.205 & 81.0 & 0.630 \\
\hline With wheelchair/walking stick $>0$ & 21 & 0 & & & & & 21 & 52.4 & & 71.4 & \\
\hline Vehicle situation & & & & & & & & & & & \\
\hline Followed by another vehicle & 435 & 67 & 83.6 & 0166 & 98.5 & 0244 & 368 & 78.5 & $<0.001$ & 88.0 & $<0.001$ \\
\hline Not followed & 502 & 125 & 90.4 & 0.166 & 95.2 & 0.244 & 377 & 59.4 & & 66.1 & \\
\hline Vehicle characteristics & & & & & & & & & & & \\
\hline Small vehicle (Car/motorcycle) & 905 & 184 & 88.6 & & 96.2 & & 721 & 69.8 & 0.003 & 77.8 & 0.001 \\
\hline Large vehicle (HGV/bus) & 32 & 8 & 75.0 & 0.247 & 100 & 0.547 & 24 & 41.7 & & 50.0 & \\
\hline Road characteristics & & & & & & & & & & & \\
\hline Link & 322 & 127 & 95.3 & & 99.2 & & 195 & 70.3 & 0.78 .5 & & \\
\hline Junction, inbound traffic & 312 & 34 & 70.6 & 0.001 & 91.2 & wa & 278 & 69.1 & $\begin{array}{cc}0.8 & 78.1\end{array}$ & 0.53 & \\
\hline Junction, outbound traffic & 303 & 31 & 77.4 & & 90.3 & & 272 & 67.7 & 74.6 & & \\
\hline Speed limit=20 $\mathrm{mph}$ & 763 & 123 & 95.1 & $<0.001$ & 99.2 & 0.005 & 640 & 69.5 & & 77.5 & 8 \\
\hline Speed limit $=30 \mathrm{mph}$ & 174 & 69 & 75.4 & & 91.3 & & 105 & 64.8 & $.3 \angle 8$ & 73.3 & 0.348 \\
\hline Raised kerb & 685 & 192 & 88.0 & & 96.4 & & 493 & 68.4 & & 75.9 & \\
\hline Not raised kerb & 252 & 0 & & & & & 252 & 69.8 & $0.6 / 9$ & 79.0 & 0.341 \\
\hline Site characteristics & & & & & & & & & & & \\
\hline Shops/services along footway & 464 & 127 & 95.3 & $<0.001$ & 99.2 & 0.003 & 337 & 74.8 & 0.002 & 82.5 & 0.001 \\
\hline No shops/services & 473 & 65 & 73.9 & & 90.8 & & 408 & 64.0 & & 72.3 & \\
\hline Time & & & & & & & & & & & \\
\hline Peak & 166 & 0 & & & & & 166 & 75.9 & & 85.5 & \\
\hline Not peak & 414 & 4 & 100 & 0.456 & 100 & 0.694 & 410 & 55.9 & ${ }_{* * *} 0.01$ & 65.1 & U. 001 \\
\hline Unknown & 357 & 188 & 87.8 & & 96.3 & & 169 & 93.5 & & 97.0 & \\
\hline Weekday & 766 & 192 & 88.0 & & 96.4 & & 574 & 66.6 & 0.013 & 73.9 & $<0.001$ \\
\hline Saturday & 171 & 0 & & & & & 171 & 76.6 & & 87.1 & \\
\hline All & 937 & 192 & 88.0 & & 96.4 & & 745 & 68.9 & & 76.9 & \\
\hline
\end{tabular}

Notes: Chi-square test significance levels: ${ }^{* * *}: 1 \%,{ }^{* *}: 5 \%,{ }^{*}: 10 \%$. p: probability; n: number 
Looking first at the frequencies of each segment, the majority of events occurred in crossing stages from footway to footway; in the first lane of traffic; without other pedestrians crossing ahead or from the opposite side; without children, older adults, and pedestrians with mobility restrictions in the group; and where the vehicle was a small one. Most of events were on weekends and in roads with $20 \mathrm{mph}$ speed limit and raised kerbs. The other sample characteristics were relatively balanced.

Looking at yielding rates, pedestrians crossing from footway to footway and those crossing the second lane with traffic in the opposite direction experienced the highest yielding rates at zebra crossings, with yielding rates equal or close to $100 \%$. In contrast, those pedestrians experienced the lowest yielding rates at courtesy crossings.

Yielding rates in the presence of other pedestrians crossing ahead or from the opposite side were significantly higher than in other situations, but only at courtesy crossings. In contrast, the presence of women and children was only significant at zebra crossings. The number of pedestrians was only significant at the $10 \%$ level at zebra crossings and the presence of pedestrians with mobility restrictions was not significant at either type of crossing. Surprisingly, events with at least one older adult had significantly lower yielding rates than other groups at courtesy crossings.

At courtesy crossings, drivers in small vehicles and in vehicles followed by another vehicle gave way to pedestrians more often than those in large vehicles and those not followed by another vehicle. The explanation for the lower propensity of vehicles that are not followed might be that the driver knows that after they clear the crossing, the pedestrian will be able to cross anyway.

Yielding rates were also higher at peak-times and on Saturdays at courtesy crossings. In contrast, the location of the crossing (junction or link) and the road's speed limit were only significant at zebra crossings. In both types of crossings, yielding rates were higher at sites with shops and services along the footway.

The segment differences affecting the propensity of the first vehicle to stop were generally similar to the differences in the propensity of any vehicle stopping. However, in zebra crossings, the differences in the propensity of any vehicle stopping were almost always significant at a lower level.

Overall, the results of this section highlight some differences between the factors explaining driver yielding behaviour at courtesy crossings and at zebra crossings, with 
different roles played by the crossing stage and the vehicle and pedestrian characteristics and situation.

\section{Modelling yielding behaviour}

Statistical models were estimated to explain how yielding behaviour in each event (i.e. every interaction between driver and pedestrians in each road lane that pedestrians need to cross) relates to the courtesy crossing design elements, when controlling for other factors.

Four models were specified, two for the propensity of the first driver stopping (Models 1 and 3) and two for the propensity of any driver stopping (Models 2 and 4). Models 1 and 2 include all crossings (zebras and courtesy crossings). The main explanatory variables are whether the crossing is a courtesy crossing (and not a zebra crossing) and the presence of the four courtesy crossing design elements. The reference case is a zebra crossing. Models 3 and 4 include only courtesy crossings. Again, the main explanatory variables of these models are the four courtesy crossing design elements. The reference case is a hypothetical courtesy crossing with none of the four specified design elements. The data from the second video survey at Crossing 7 (after the design of the crossing was changed) was not included in any model. The sample sizes are therefore 774 events in Models 1 and 2 and 582 events in Models 3 and 4.

In all models, the control variables identify crossing stage, pedestrian and vehicle characteristics and situation, road and site characteristics, and time of day. Using a bidirectional elimination process, variables that were not significant at the $10 \%$ level were excluded. Independence between explanatory variables was checked using variance inflation factors. This led to the exclusion of the dummy variable for Saturdays.

The models used a logistic specification. The dependent variables are the log odds of the first vehicle stopping (in Models 1 and 3) or any vehicle stopping (in Models 2 and 4) vs. not stopping. The standard errors of the model coefficients were clustered by crossing, to account for possible correlation in the errors for events occurring in the same crossing.

Table 6 shows the estimated models. The models fitted well with the data, as shown in the three goodness of fit statistics reported at the bottom of the table. In particular, the models for the propensity of any vehicle stopping for pedestrians correctly predicted the outcome (stop vs. not) in $85 \%-87 \%$ of the cases. 
Table 6: Models of driver yielding behaviour

\begin{tabular}{|c|c|c|c|c|c|c|c|c|}
\hline \multirow{3}{*}{ Variable } & \multicolumn{4}{|c|}{ All crossings } & \multicolumn{4}{|c|}{ Courtesy crossings } \\
\hline & \multicolumn{2}{|c|}{$\begin{array}{c}\text { Model 1 } \\
\text { First vehicle } \\
\text { stops } \\
\end{array}$} & \multicolumn{2}{|c|}{$\begin{array}{c}\text { Model } 2 \\
\text { Any vehicle } \\
\text { stops }\end{array}$} & \multicolumn{2}{|c|}{$\begin{array}{c}\text { Model 3 } \\
\text { First vehicle } \\
\text { stops }\end{array}$} & \multicolumn{2}{|c|}{$\begin{array}{c}\text { Model } 4 \\
\text { Any vehicle } \\
\text { stops }\end{array}$} \\
\hline & & SE & Coeff. & SE & Coeff. & SE & Coeff. & SE \\
\hline Constant & -0.89 & 0.76 & -3.26 & $1.47^{* *}$ & -4.31 & $1.02^{* * * *}$ & -9.04 & $2.16^{* *}$ \\
\hline \multicolumn{9}{|l|}{ Courtesy crossing design elements } \\
\hline Any (Courtesy crossing) & -4.20 & $0.65^{* * * *}$ & -5.68 & $0.66^{* * * *}$ & & & & \\
\hline Stripes (not zebra-like) & 1.49 & $0.63^{* *}$ & 1.90 & $0.59^{* * * *}$ & 1.68 & $0.79^{* *}$ & 1.80 & $0.62^{* * *}$ \\
\hline Colour treatment & 1.47 & $0.50^{* * * *}$ & 1.03 & $0.39^{* * *}$ & 1.35 & $0.57^{* *}$ & 1.11 & $0.34^{* * *}$ \\
\hline Visual narrowing of carriageway & 1.55 & $0.64^{* *}$ & 2.91 & $0.81^{* * * *}$ & 1.38 & $0.66^{* *}$ & 3.00 & $0.94^{* * *}$ \\
\hline Ramps & 1.53 & $0.73^{* *}$ & 2.07 & $0.54^{* * *}$ & 1.47 & $0.75^{* *}$ & 2.21 & $0.55^{* * *}$ \\
\hline \multicolumn{9}{|l|}{ Crossing stage } \\
\hline From median strip to footv & 2.41 & $0.65^{* * *}$ & 4.79 & $1.26^{* * * *}$ & 2.29 & $0.78^{* * * *}$ & 5.14 & $1.48^{* * *}$ \\
\hline From footway to median strip & 1.38 & $0.46^{* * *}$ & 4.19 & $1.41^{* * * *}$ & 1.36 & $0.75^{*}$ & 4.60 & $1.93^{* *}$ \\
\hline Second lane & 1.25 & $0.53^{*}$ & & & 0.67 & $0.24^{* * * * *}$ & & \\
\hline Second lane (in opposite direction) & 0.90 & $0.27^{* * * *}$ & & & & & & \\
\hline \multicolumn{9}{|l|}{$\overline{P e d e s t r i a n ~ s i t u a t i o n}$} \\
\hline Group & 0.43 & $0.24^{*}$ & & & 0.58 & $0.26^{* *}$ & & \\
\hline Others crossing & 1.17 & $0.26^{* * * *}$ & & & 1.39 & $0.37^{* * * *}$ & 0.63 & $0.33^{*}$ \\
\hline Others crossing from othe & 1.98 & $0.53^{* * *}$ & 1.39 & $0.31^{* * *}$ & 1.96 & $0.58^{* * *}$ & 1.39 & $0.33^{* * *}$ \\
\hline \multicolumn{9}{|l|}{ Pedestrian characteristics } \\
\hline Female $>0$ & 0.52 & $0.23^{* *}$ & 0.85 & $0.22^{* * *}$ & & & 0.83 & $0.22^{* * *}$ \\
\hline \multicolumn{9}{|l|}{ Vehicle situation } \\
\hline Followed by another vehicle & 0.82 & $0.25^{* * *}$ & 1.61 & $0.42^{* * *}$ & 0.69 & $0.25^{* * *}$ & 1.41 & $0.41^{* * *}$ \\
\hline \multicolumn{9}{|l|}{ Other infrastructure characteristics } \\
\hline Junction, inbound traffic & -1.47 & $0.63^{* *}$ & & & -1.29 & $0.75^{*}$ & & \\
\hline Junction, outbound traffic & -1.49 & $0.70^{* *}$ & & & -1.37 & $0.82^{*}$ & & \\
\hline Speed limit=20mph & 1.44 & $0.54^{* * *}$ & 4.26 & $1.05^{* * *}$ & 1.14 & $0.55^{* *}$ & 4.31 & $1.32^{* * * *}$ \\
\hline \multicolumn{9}{|l|}{ Site characteristics } \\
\hline Shops & 1.09 & $0.52^{* *}$ & 2.61 & $0.60^{* * *}$ & 0.90 & $0.55^{*}$ & 2.40 & $0.67^{* * *}$ \\
\hline Number of observati & & 774 & & 774 & & 82 & & 582 \\
\hline McFadden's Pseudo R ${ }^{2}$ & & 0.32 & & .41 & & .30 & & 0.43 \\
\hline Count $\mathbf{R}^{2}$ & & 0.68 & & .87 & & .61 & & 0.85 \\
\hline Adjusted Count $\mathbf{R}^{2}$ & & 0.40 & & .44 & & .46 & & 0.48 \\
\hline \multicolumn{9}{|c|}{$\begin{array}{l}\text { Notes: Significance levels: }: 1 \%,: 5 \%, ": 10 \% \text {; Coeff: coefficient; SE: standard error. Omitted } \\
\text { categories: zebra crossings [Model } 1 \text { and } 2 \text { ], courtesy crossing with none of the specified design elements } \\
\text { [Models } 3 \text { and 4]; from footway to footway; first lane; no others crossing together, ahead, or from other } \\
\text { side; no women in the group, vehicle not followed; speed limit=30mph; no shops along footway. Goodness } \\
\text { of fit statistics: McFadden's Pseudo } \mathrm{R}^{2} \text { is the reduction in log-likelihood of final model compared with } \\
\text { intercept-only model; Count } \mathrm{R}^{2} \text { is the proportion of correct predictions; Adjusted Count } \mathrm{R}^{2} \text { is the proportion } \\
\text { of correct predictions beyond what would be correctly predicted by assigning the most frequent outcome to } \\
\text { all observations. }\end{array}$} \\
\hline
\end{tabular}

The coefficients of the four courtesy crossing design elements were positive in all models and significant at the 1\% level (in Models 2 and 4) and at the 5\% level (in Models 1 and 3 except colour treatment, significant at the $1 \%$ level in Model 1). This result means that each additional design element contributed to a higher propensity of drivers yielding to pedestrians. The impacts of each element on the propensity of the first driver stopping (Models 1 and 3) had similar magnitudes, with only a slightly higher impact for stripes in Model 3. The impacts 
on the propensity of any driver stopping (Models 2 and 4) were less balanced, with visual narrowing having a considerably larger impact than the other elements.

The impact of combinations of courtesy crossing design elements is given by the sum of the coefficients of those elements. In Model 1, combinations of any three courtesy crossing design elements had a higher impact on the propensity of the first vehicle stopping for pedestrians than zebra crossings, as the sum of the coefficients of any three elements was higher, in absolute value, than the (negative) coefficient for courtesy crossings (vs. zebras). In Model 2, combinations of three design elements that include visual narrowing also had a higher impact on the propensity of any vehicle stopping for pedestrians than zebra crossings. The 3-element combination of design elements with the highest impact, in both models, is the one with visual narrowing, ramps, and strips.

In all models, there was a higher propensity for yielding behaviour when (i) pedestrians were crossing from or to the median strip, (ii) with other pedestrians crossing from the other side, (iii) the vehicle was followed by another vehicle, (iv) the road had a $20 \mathrm{mph}$ speed limit, and (v) there were shops along the footway.

Additional variables were significant in Models 1 and 3. The propensity of the first driver giving way to pedestrians was higher when (i) pedestrians were crossing the second lane with traffic in the same direction, (ii) were crossing in a group, (iii) with other pedestrians crossing ahead, and (iv) the crossing was on a link (not a junction). In Model 1, the propensity was also higher when (i) pedestrians were crossing the second lane with traffic in the opposite direction and (ii) there was at least one woman in the group. In Models 2 and 4, the presence of a woman in the group was also significant.

With regards to the magnitude of coefficients in the same group of variables, the coefficients were higher for: i) crossing from the median strip, compared with crossing to the median strip, and ii) other pedestrians crossing from the other side, compared with others crossing ahead or crossing together in the same group. Where significant, the coefficients of inbound and outbound traffic on a junction were similar.

Insignificant variables, tested in preliminary runs of the models and excluded from all final models, included whether the group includes a child, an older adult, or a pedestrian with mobility restrictions, size of vehicles, whether the kerb is raised, and time of day.

The results of the models were generally consistent with the bivariate analysis reported in Table 5. However, some significant differences between segments became insignificant when controlling for other variables in the logistic regression. This includes the unexpected result in 
Table 5 of lower yielding rates at courtesy crossings when there were older adults in the group. A few insignificant differences between segments also became significant in the logistic regression (e.g. speed limit at courtesy crossings).

\section{Impact of adding a design element to an existing crossing}

There were changes to the design of one of the crossings (Crossing 7, Kimbrose Triangle, Gloucester), which allowed us to test how driver yielding behaviour responds to the addition of a new design element to an existing courtesy crossing (Figure 3). When the crossing was originally completed in 2011, the only courtesy crossing design element was the visual narrowing of the carriageway. Stripes were added in early 2015, following requests by users and a consultation process. The stripes have some resemblance to zebra crossing stripes, but the crossing is not a formal zebra crossing, as drivers are not legally required to stop. In addition, the crossing does not have the required standardized design elements of zebras, such as signs, posts with flashing lights, and zigzag markings.

Two sets of video surveys were conducted at this site, before (August 2014) and after (February 2015) the addition of the stripes. Driver yielding behaviour and event-specific variables were recorded for both situations, using the methods described in Section 3.

Figure 3: Kimbrose Triangle: before and after
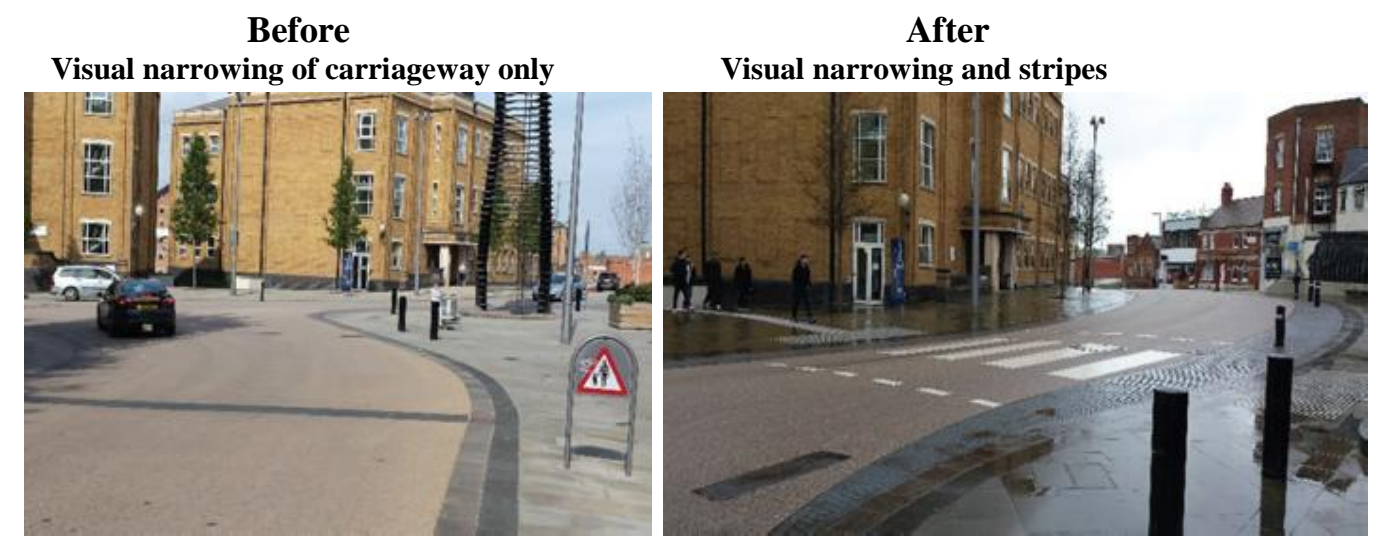

Source: CIHT (2018)

The proportion of events where the first vehicle stopped for pedestrians increased dramatically from $20.2 \%$ to $96.9 \%$ and the proportion where any vehicle stopped increased from $41.6 \%$ to $99.4 \%$. These increases happened in all segments of the sample, as shown in Table 7 . The yielding rates after the change were $100 \%$ for several segments. The differences between the before and after yielding rates were significant at the $1 \%$ level in all segments. 
Table 7: Yielding rates in Kimbrose Triangle crossing by segment, before and after adding stripes

\begin{tabular}{|c|c|c|c|c|c|c|c|c|}
\hline \multirow[t]{2}{*}{ Variable } & \multicolumn{2}{|c|}{$\mathbf{N}$} & \multicolumn{3}{|c|}{$\begin{array}{c}\text { \% first vehicle } \\
\text { stops }\end{array}$} & \multicolumn{3}{|c|}{$\begin{array}{c}\% \text { any vehicle } \\
\text { stops }\end{array}$} \\
\hline & Before & After & Before & After & & Before & After & \\
\hline \multicolumn{9}{|l|}{ Crossing stage } \\
\hline First Lane & 44 & 83 & 15.9 & 96.4 & $* * *$ & 38.6 & 98.9 & $* * *$ \\
\hline Second Lane (in opposite direction) & 45 & 80 & 24.4 & 97.5 & $* * *$ & 44.4 & 100 & $* * *$ \\
\hline \multicolumn{9}{|l|}{ Pedestrian situation } \\
\hline Single pedestrian & 37 & 78 & 21.6 & 98.7 & $* * *$ & 37.8 & 100 & *** \\
\hline Group & 52 & 85 & 19.2 & 95.3 & **** & 44.2 & 98.8 & \\
\hline No others & 69 & 90 & 15.9 & 94.4 & & 37.7 & 98.9 & \\
\hline Others crossing ahead & 3 & 30 & 33.3 & 100 & *** & 66.7 & 100 & $* * *$ \\
\hline Others crossing from oppposite side & 17 & 51 & 35.3 & 100 & $* * * *$ & 52.9 & 100 & **** \\
\hline \multicolumn{9}{|l|}{ Pedestrian characteristics } \\
\hline Female $>0$ & 60 & 86 & 21.7 & 95.4 & $* * *$ & 48.3 & 98.8 & $* * *$ \\
\hline Female $=0$ & 29 & 77 & 17.2 & 98.7 & **** & 27.6 & 100 & **** \\
\hline All & 89 & 163 & 20.2 & 96.9 & & 41.6 & 99.4 & \\
\hline
\end{tabular}

Notes: Chi-square test significance levels: ${ }^{* * *}: 1 \%,{ }^{* *}: 5 \%,{ }^{*}: 10 \%$. Age of pedestrians and vehicle situation and characteristics not shown because of small samples in the "after" situation of groups with children or older adults, large vehicles, and vehicles not followed by another vehicle.

Logistic models were estimated on a dataset merging data for the before and after situation in this crossing. The dependent variables represent the case of the first driver stopping (Model 1) and any driver stopping (Model 2). The main explanatory variable is a dummy for the presence of stripes (i.e. the "after" situation). The control variables identify pedestrian and vehicle situation and characteristics and crossing stage - in this case, defined only by second lane with traffic in the opposite direction, as the crossing has no median strip.

Table 8 shows the estimated models. The two models fitted well with the data, as shown in the three goodness of fit measures reported. The coefficient identifying stripes was positive and significant at the $1 \%$ level in both models, which means that the presence of stripes was associated with driver yielding behaviour, even when controlling for other factors affecting this behaviour.

Among the control variables, the probability of the first driver stopping was higher when there were pedestrians crossing from the opposite side and the vehicle was followed by another vehicle or was a small vehicle (although in this last case, the level of significance was only $10 \%)$. The probability of any driver stopping was higher when there were pedestrians crossing from the opposite side, there were women in the group, and the vehicle was followed by another vehicle. Where significant, the signs of the significant variables were the same as the signs in the cross-sectional models in Table 6.

Insignificant variables, tested in preliminary runs of the model and excluded from the final model, include crossing the second lane with traffic in the opposite direction, pedestrians 
crossing in a group, other pedestrians crossing ahead, and whether the group included a child, an older adult, or a pedestrian with mobility restrictions.

Table 8: Before-after model, Kimbrose Triangle crossing

\begin{tabular}{|c|c|c|c|c|c|c|}
\hline \multirow{2}{*}{ Variable } & \multicolumn{3}{|c|}{$\begin{array}{c}\text { Model } 1 \\
\text { First vehicle stops } \\
\end{array}$} & \multicolumn{3}{|c|}{$\begin{array}{c}\text { Model } 2 \\
\text { Any vehicle stops }\end{array}$} \\
\hline & Coefficient & $\begin{array}{c}\text { Standard } \\
\text { error }\end{array}$ & & Coefficient & $\begin{array}{c}\text { Standard } \\
\text { error }\end{array}$ & \\
\hline Constant & -2.08 & 0.43 & & -1.72 & 0.52 & \\
\hline $\begin{array}{l}\text { Courtesy crossing characteristics } \\
\text { Stripes ["after" situation] }\end{array}$ & 4.54 & 0.64 & $* * *$ & 4.83 & 1.08 & $* * *$ \\
\hline $\begin{array}{l}\text { Pedestrian situation } \\
\text { Others crossing from other side }\end{array}$ & 1.45 & 0.60 & *** & 1.16 & 0.60 & $* *$ \\
\hline $\begin{array}{l}\text { Pedestrian characteristics } \\
\text { Female }>0\end{array}$ & & & & 0.98 & 0.50 & $* *$ \\
\hline $\begin{array}{l}\text { Vehicle situation } \\
\text { Followed by another vehicle }\end{array}$ & 0.98 & 0.57 & ** & 1.46 & 0.51 & $* * *$ \\
\hline $\begin{array}{l}\text { Vehicle characteristics } \\
\text { Large vehicle (HGV/Bus) }\end{array}$ & -3.44 & 1.50 & * & & & \\
\hline $\begin{array}{l}\text { Number of observations } \\
\text { McFadden's Pseudo } \mathbf{R}^{2} \\
\text { Count } \mathbf{R}^{2} \\
\text { Adjusted Count } \mathbf{R}^{2} \\
\end{array}$ & $\begin{array}{l}252 \\
0.5 \\
0.8 \\
0.4 \\
\end{array}$ & & & $\begin{array}{l}25 \\
0 . \\
0 . \\
0 .\end{array}$ & & \\
\hline
\end{tabular}

Notes: Significance levels: ${ }^{* * *}: 1 \%,{ }^{* *}: 5 \%,{ }^{*}: 10 \%$. Omitted categories: no stripes, no others crossing from other side, no women in the group, vehicle not followed by another, small vehicle. Interpretation of goodness of fit statistics: see Table 6 .

\section{Discussion}

\section{Synthesis and relation to previous literature}

There is a movement towards the provision of more courtesy crossings, where drivers are not legally required to stop but may do so out of courtesy. However, there is still little quantitative evidence on how different design elements of courtesy crossings influence driver yielding behaviour to pedestrians. This study has filled this gap by comparing driver yielding behaviour at courtesy crossings and marked unsignalised crossings (zebras), and identifying the design elements associated with yielding behaviour at courtesy crossings. Unlike most previous studies on vehicle-pedestrian interactions, we analysed driver yielding behaviour in each separate traffic lane that pedestrians need to cross.

Using cross-sectional data from 20 different crossings, we found that all four design elements of courtesy crossings considered (stripes, coloured or textured surfacing, visual narrowing of the road, and ramps) significantly increased yielding behaviour. This was further confirmed in the analysis of before-after data in a location where an additional element (stripes) was added to an existing courtesy crossing. 
The results also provided insights into the motivations of driver yielding behaviour in response to factors other than the design of the crossings, highlighting how those motivations differed in courtesy crossings and in zebras. This is evident in the differences between yielding rates at the two types of crossings (as shown in Table 5) and in how other results for courtesy crossings compare with those in the previous literature on marked unsignalised crossings (listed in Table 1). In some cases, our results confirmed those in the literature. For example, drivers tend to stop more often in when the speed limit is lower and when pedestrians are crossing the second lane of traffic. In other cases, the results add evidence regarding factors for which previous evidence was mixed. For example, yielding rates were higher when pedestrians are crossing from or to a median strip and when the vehicle was followed by another vehicle. Yet, in other cases, the results did not confirm previous evidence. For example, we found only weak or no evidence that yielding rates increased with the number of pedestrians crossing in each event and when there were children, older adults, and pedestrians with mobility restrictions in the group.

\section{Implications for policy and practice}

Our results address the calls for evidence requested by policy-makers and professional associations on the design of courtesy crossings. Based on the results found, we recommend that the design of courtesy crossings includes all four design elements analysed, where possible. Median strips and lower speed limits are additional elements that could increase driver yielding behaviour. In fact, these elements could be considered in themselves as courtesy crossing design elements. These recommendations are made with the caveat that the supporting results were obtained in the specific context of the UK. Whether the recommendations apply in other countries depends on regulations, availability of other types of crossings, and perhaps on demographic and cultural factors.

Our results also have implications for the location of courtesy crossings, i.e. in which type of roads and which particular places these crossings could be installed. For example, the results in the models in Table 6 suggest that yielding rates at courtesy crossings were significantly higher at sites where there are shops and services along the footway.

Finally, the results add to the debate on "shared space". We found that marginal differences in the road design influence the behaviour of drivers of motorised vehicles, which suggests that these differences increase drivers' feeling that they should share the space with pedestrians - one of the main assumptions of courtesy crossings and the wider shared space philosophy. Some combinations of design elements (in fact, any combination of three of the 
four design elements studied) are even more effective in inducing yielding behaviour than traffic regulations (i.e. the legal requirement to stop at zebra crossings). As such, road design alone can contribute to the reduction of the dominance of motorised vehicles, addressing some of the needs of pedestrians and people using roads and streets for place activities. These results may also apply to other users of non-motorised transport, such as cyclists and people using skateboards or scooters.

\section{Directions for future research}

The other main assumption of courtesy crossings and of the wider shared space approach that it effectively addresses pedestrian safety - needs further evidence. While yielding rates could be understood as an indicator of pedestrian safety, more solid conclusions on this aspect require measuring the relationships between courtesy crossing design elements; yielding behaviour; and collision risk or pedestrian perceptions of risk. In addition, yielding rates alone do not fully capture driver behaviour: the speed of vehicles approaching the crossings, regardless of whether they stop for pedestrians or not, is also important. Evidence suggests that zebra crossings do not effectively reduce vehicle speeds even in roads with a low speed limit of 30kph (18.6 mph) (Johansson et al. 2003), a result that may also apply to courtesy crossings.

We also note that this paper looked at driver behaviour at different types of crossings, which is only one side of the problem. The choice over the most suitable type of crossings also depends on pedestrian perceptions and behaviour, which may be influenced by different design elements. It is particularly important to study the degree to which courtesy crossings address the mobility and safety of pedestrians with mobility, visual, or other physical impairments.

The role of time in changing yielding behaviour can also be further explored. Our beforeafter analysis considered the change over two points in time (with a year interval). A more regular monitoring of yielding rates (together with opinion surveys) could explain the process of how drivers and pedestrians adapt to changes in the crossing design. A monitoring period longer than one year can also identify any possible rebound in yielding rates after the initial adjustment.

A few methodological refinements could be introduced in future research. For example, due to limitations arising from the location of the video cameras, we could not account for the full range of attributes of factors affecting driver behaviour, such as the trajectory followed by 
vehicles (e.g. curves, deviations, turning movements at junctions). The use of automated video analysis could also improve the identification of all possible driver-pedestrian interactions as pedestrians move across the road (Laureshyn et al. 2010), rather than only at the start of each road lane. Using a larger sample of crossings, the set of design elements could also be disaggregated into different types of stripes, colours, and textures. To have a better understanding of yielding behaviour, it would also be beneficial to validate model results with surveys or focus groups to capture nuances in driver perceptions, attitudes, and preferences.

\section{Acknowledgments}

The authors would like to thank Phil Jones (Phil Jones Associates) and Chris Oakley (Crowd Dynamics International Limited) for making available the videos for analysis and Transport Planning Associates for sponsoring the studies of Giovanni Di Guardo at Imperial College London and UCL as part of which a preliminary version of this research was undertaken.

\section{References}

Al-Kaisy, A., Miyake, G T., Staszcuk, J., Scharf, D. (2017) Motorists' voluntary yielding of right of way at uncontrolled midblock crosswalks. Journal of Transportation Safety and Security 10, 303-317.

Almodfer, R., Xiong, S., Fang, Z., Kong, X., Zheng, S. (2016) Quantitative analysis of lane-based pedestrian-vehicle conflict at a non-signalized marked crosswalk. Transportation Research Part F: Traffic Psychology and Behaviour 42, 468-178.

Bella, F., Silvestri, M. (2015) Effects of safety measures on driver's speed behaviour at pedestrian crossings. Accident Analysis and Prevention 83, 111-124.

Bennett, M K., Manal, H., Van Houten, R. (2014) A comparison of gateway in-street sign configuration to other driver prompts to increase yielding to pedestrians and crosswalks. Journal of Applied Behaviour Analysis 47, 3-15.

Bourquin, E., Emerson, R W., Sauerburger, D. (2011) Conditions that influence drivers' yielding behavior for uncontrolled intersections. Journal of Visual Impairment and Blindness 105, 760-769.

CIHT (Chartered Institution of Highways and Transportation) (2018) Creating Better Streets: Inclusive and Accessible Places. Reviewing Shared Space. CIHT, London., https://www.ciht.org.uk/media/4463/ciht_shared_streets_a4_v6_all_combined_1.pdf

Coughenour, C., Clark, S., Singh, A., Claw, E., Abelar, J., Huebner, J. (2017) Examining racial bias as a potential factor in pedestrian crashes. Accident Analysis and Prevention 98, 96-100. 
Craig, C M., Morris, N L., Hong, Y. (2019a) A case study on the impact of crosswalk markings on driver yielding to pedestrians. Proceedings of the Human Factors and Ergonomics Society Annual Meeting 63, 1399-1403.

Craig, C M., Morris, N L., Hong, Y. (2019b) Pedestrian safety and driver yielding near public transit stops. Transportation Research Record 2673, 514-523.

DfT (Department for Transport, UK) (1995) The Assessment of Pedestrian Crossings. Local Transport Note 1/95. The Stationary Office, London., https://www.gov.uk/government/publications/the-assessment-ofpedestrian-crossings-ltn-195

DfT (Department for Transport, UK) (2011) Shared Space. Local Transport Note 1/11 [Withdrawn]. The Stationary Office, London., https://www.gov.uk/government/publications/shared-space

DfT (Department for Transport, UK) (2018) Ministerial letter to local authorities about the shared space schemes., https://assets.publishing.service.gov.uk/government/uploads/system/uploads/attachment data/ file/749116/ministerial-letter-about-shared_space.pdf

Figliozzi, M A., Tipagornwong, C. (2016) Pedestrian Crosswalk Law: a study of traffic and trajectory factors that affect non-compliance and stopping distance. Accident Analysis and Prevention 96, 169-179.

Fisher, D., Garay-Vega, L. (2012) Advance yield markings and drivers' performance in response to multiple-threat scenarios at mid-block crosswalks. Accident Analysis and Prevention 44, 35-51.

Forster, A. (2014) Blind groups press council to scrap courtesy crossing plans. Local Transport Today 645.

Foster, N., Monsere, C M., Carlos, K. (2014) Evaluating driver and pedestrian behaviors at enhanced, multilane, midblock pedestrian crossings. Transportation Research Record 2464, 59-66.

Geruschat, D R., Hassan, S. E. (2005) Driver behavior in yielding to sighted and blind pedestrians at roundabouts. Journal of Visual Impairment and Blindness 99, 286-02.

Gitelman, V., Balasha, D., Carmel, R., Hendel, L., Pesahov, F. (2012) Characterization of pedestrian accidents and an examination of infrastructure measures to improve pedestrian safety in Israel. Accident Analysis and Prevention 44, 63-73.

Gitelman, V., Carmel, R., Pesahov, F., Hakkert, S. (2017a) An examination of the influence of crosswalk marking removal on pedestrian safety as reflected in road user behaviours. Transportation Research Part F: Traffic Psychology and Behaviour 46, 342-355.

Gitelman, V., Carmel, R., Pesahov, F., Chen, S. (2017b) Changes in road-user behaviors following the installation of raised pedestrian crosswalks combined with preceding speed humps, on urban arterials. Transportation Research Part F: Traffic Psychology and Behaviour 46, 356-372.

Goddard, T., Kahn, K B., Adkins, A. (2015) Racial bias in driver yielding behavior at crosswalks. Transportation Research Part F: Traffic Psychology and Behaviour 33, 1-6.

Gorrini, A., Crociani, L., Vizzari, G., Bandini, S. (2018) Observation results on pedestrian-vehicle interactions at non-signalized intersections towards simulation. Transportation Research Part F: Traffic Psychology and Behaviour 33, 269-295.

Guéguen, N., Eyssartier, C., Meineri, S. (2016) A pedestrian's smile and drivers' behavior: when a smile increases careful driving. Journal of Safety Research 56, 83-88. 
Hamilton-Baillie, B. (2008a) Towards shared space. Urban Design International 13, 130-138.

Hamilton-Baillie, B. (2008b) Shared space: reconciling people, places and traffic. Built Environment 34 (2), 161-181.

Hammond, V., Musselwhite, C. (2013) The attitudes, perceptions and concerns of pedestrians and vulnerable road users to shared space: a case study from the UK. Journal of Urban Design 18, 78-97.

Harrell, W A. (1992) Driver response to a disabled pedestrian using a dangerous crosswalk. Journal of Environmental Psychology 12, 345-354.

Harrell, W A. (1993) The impact of pedestrian visibility and assertiveness on motorist yielding. Journal of Social Psychology 133, 353-360.

Havard, C. Willis, A. (2012) Effects of installing a marked crosswalk on road crossing behaviour and perceptions of the environment. Transportation Research Part F: Traffic Psychology and Behaviour 15, 249-260.

Havik, E M., Melis-Dankers, B J M., Steyvers, F J J M., Kooijman, A C. (2012) Accessibility of shared space for visually impaired persons: an inventory in the Netherlands. The British Journal of Visual Impairment 30, 132-148.

Havik, E M., Steyvers, F J J M., Kooijman, A C., Melis-Dankers, B J M. (2015) Accessibility of shared space for visually impaired persons: a comparative field study. The British Journal of Visual Impairment 33, 96-110.

Horrell, T., Jones, P. (2014) What are the effects of a 'shared space' scheme on different users? Proceedings of the 13th Annual Transport Practitioners' Meeting. PTRC Education and Research Services Limited, London., https://discovery.ucl.ac.uk/id/eprint/1503196

Høye, A., Laureshyn, A. (2019) SeeMe at the crosswalk: before-after study of a pedestrian crosswalk warning system. Transportation Research Part F: Traffic Psychology and Behaviour 60, 723-733.

Imrie, R. (2012) Auto-disabilities: the case of shared space environments. Environment and Planning A: Economy and Space 44, 2260-2277.

Imrie, R. (2013) Shared space and the post-politics of environmental change. Urban Studies 50, 3446-3462.

Johansson, C., Gårder, P., Leden, L. (2003) Toward Vision Zero at zebra crossings case study of traffic safety and mobility for children and the elderly, Malmö, Sweden. Transportation Research Record 1828, 67-74.

Kaparias, I., Bell, M G H., Miri, A., Chan, C., Mount, B. (2012) Analysing the perceptions of pedestrians and drivers to shared space. Transportation Research Part F: Traffic Psychology and Behaviour 15, 297310.

Knoblauch, R L., Nitzburg, M., Seifert, R L. (2001) Pedestrian Crosswalk Case Studies: Richmond, Virginia; Buffalo, New York; Stillwater, Minnesota. Report for Federal Highway Administration, US Department of Transportation., https://www.fhwa.dot.gov/publications/research/safety/00103/00103.pdf

Laureshyn, A., Svensson, Å., Hydén, C. (2010) Evaluation of traffic safety, based on micro-level behavioural data: Theoretical framework and first implementation. Accident Analysis and Prevention 42, 1637-1646. 
Malenje, J O., Zhao, J., Li, P., Han, Y. (2019) Vehicle yielding probability estimation model at unsignalized midblock crosswalks in Shanghai, China. PLoS ONE 14: e0213876

Methorst, R. (2007) Shared space: safe or dangerous? A contribution to objectification of a popular design philosophy. Proceedings of WALK21 Conference, Toronto, Canada, 1-3 October 2007.

Mitman, M F., Ragland, D R., Zegeer, C V. (2008) Marked-crosswalk dilemma - uncovering some missing links in a 35-year debate. Transportation Research Record 2073, 86-93.

Moody, S., Melia, S. (2014) Shared space - research, policy and problems. Proceedings of the Institution of Civil Engineers - Transport 167, 384-392.

Morency, P., Archambault, J., Cloutier, M-S., Tremblay, M., Plante, C. (2015) Major urban road characteristics and injured pedestrians: A representative survey of intersections in Montréal, Quebec. Canadian Journal of Public Health 106, e388-e394.

MVA (2010) Designing the Future - Shared Space: Operational Assessment. Report for Department for Transport., LTN 1/11 supporting documents, The Stationary Office, London., https://www.gov.uk/government/publications/shared-space

Obeid, H., Abkarian, H., Abou-Zeid, M. (2017) Analyzing driver-pedestrian interaction in a mixed-street environment using a driving simulator. Accident Analysis and Prevention 108, 56-65.

Porter, B E., Neto, I., Balk, I., Jenkins, J K. (2016) Investigating the effects of Rectangular Rapid Flash Beacons on pedestrian behavior and driver yielding on $25 \mathrm{mph}$ streets: a quasi-experimental field study on a university campus. Transportation Research Part F: Traffic Psychology and Behaviour 42, 509521.

Pulugurtha, S S., Vasudevan, V., Nambisan, S S., Dangeti, M R. (2012) Evaluating effectiveness of infrastructure-based countermeasures for pedestrian safety. Transportation Research Record 2299, 100109.

Rosenbloom, T., Nemrodov, D., Eliyahu, A B. (2006) Yielding behavior of Israeli drivers: interaction of age and sex. Perceptual and Motor Skills 103, 387-390.

Sandt, L S., Marshall, S W., Rodriguez, D A., Evenson, K R., Ennett, S T., Robinson, W R. (2016) Effect of a community-based pedestrian injury prevention program on driver yielding behavior at marked crosswalks. Accident Analysis and Prevention 93, 169-178.

Schneider, R J., Sanatizadeh, A., Shaon, M R R., He, Z., Qin, X. (2018) Exploratory analysis of driver yielding at low-speed, uncontrolled crosswalks in Milwaukee, Wisconsin. Transportation Research Record 2672, 21-32.

Schroeder B J., Rouphail N M. (2011) Event-based modelling of driver yielding behavior at unsignalized crosswalks. Journal of Transportation Engineering 137, 455-465.

Stapleton, S., Kirsch, T., Gates, T J., Savolainen, P T. (2017) Factors affecting driver yielding compliance at uncontrolled midblock crosswalks on low-speed roadways. Transportation Research Record 2661, 95102.

Strong, C., Ye, Z. (2010) Spillover effects of yield-to-pedestrian channelizing devices. Safety Science 48, 342-347. 
Sucha, M., Dostal, D., Risser R. (2017) Pedestrian-driver communication and decision strategies at marked crossings. Accident Analysis and Prevention 102, 41-50.

Thulin, H. (2007) Uppföljning av Regeln om Väjningsplikt För Fordonsförare Mot Fotgängare På Obevakat Övergångsställe - Trafiksäkerhetseffekten [Monitoring of the regulation obliging drivers to give way to pedestrians on zebra crossings]. VTI Rapport 597. Swedish National Road and Transport Research Institute, Linköping., https://www.vti.se/sv/Publikationer/Publikation/uppfoljning-av-regelnom-vajningsplikt-for-fordons_675332 [In Swedish]

Zhang, C., Zhou, B., Chen, G., Chen, F. (2017) Quantitative analysis of pedestrian safety at uncontrolled multi-lane mid-block crosswalks in China. Accident Analysis and Prevention 108, 19-26. 


\section{Appendix: Detailed designs of the case study crossings}
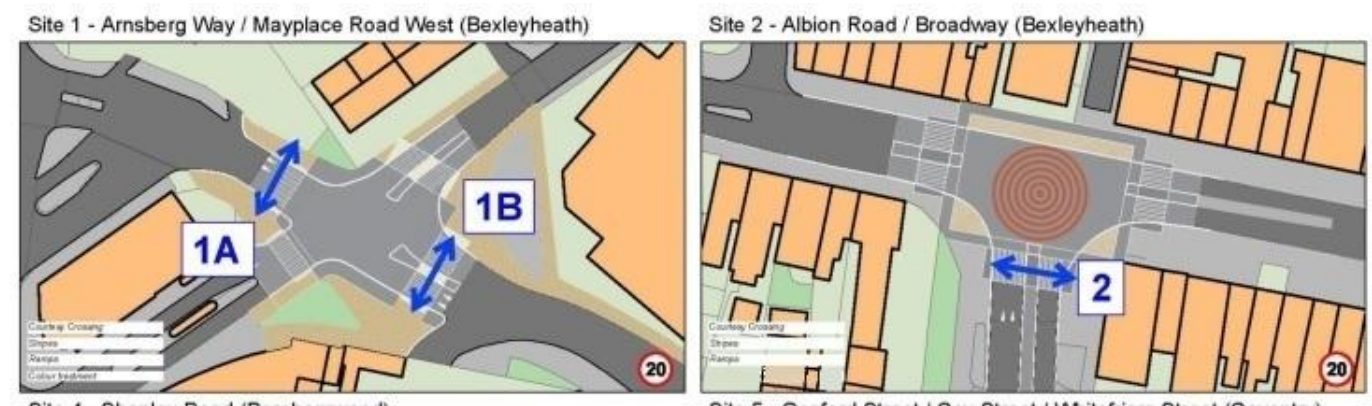

Site 3- The Blackpool Tower (Blackpool)

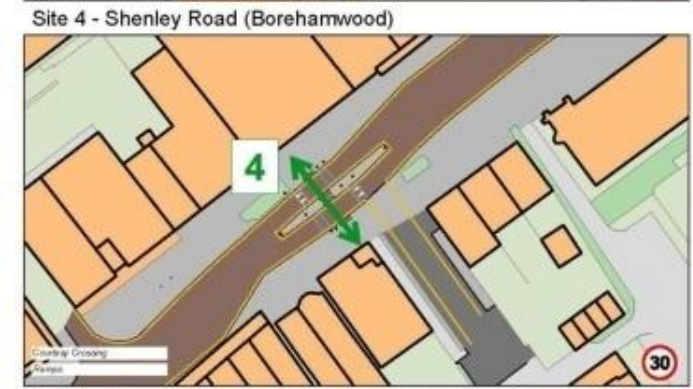

Site 5-Gosford Street/ Cox Street / Whitefriars Street (Coventry) Site 6- Hamilton Road / Cobbold Road (Felixstowe)

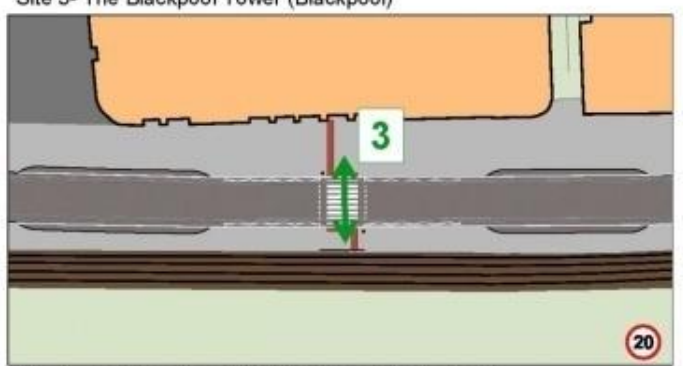

(20)
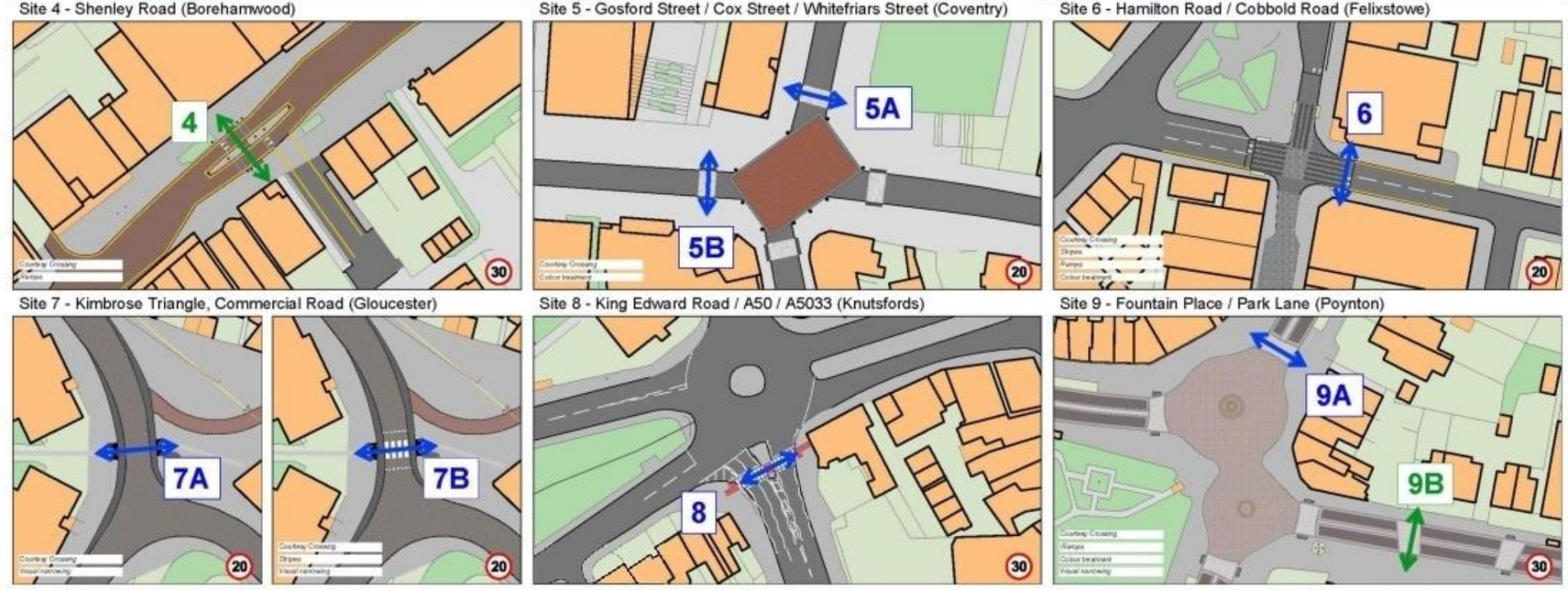

Site 10 - Park Lane / Bulkeley Road (Poynton)
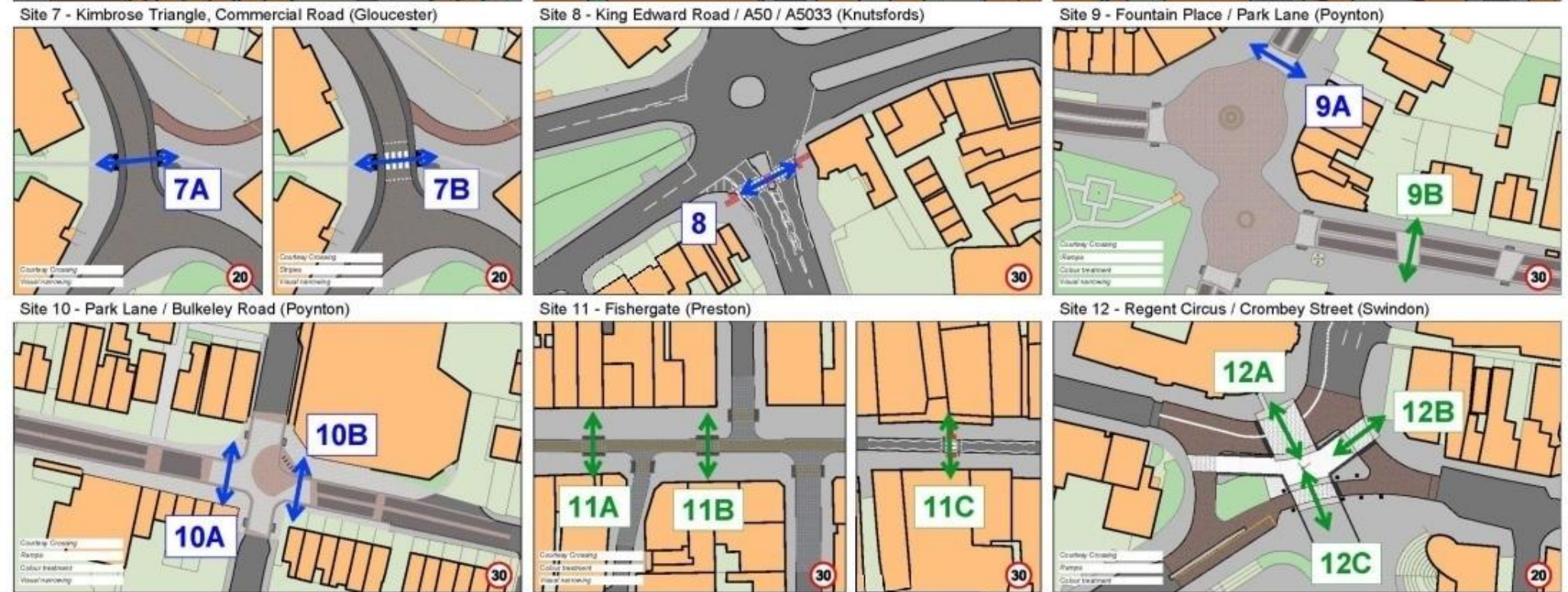

Site 11 - Fishergate (Preston)

Site 12 - Regent Circus / Crombey Street (Swindon)
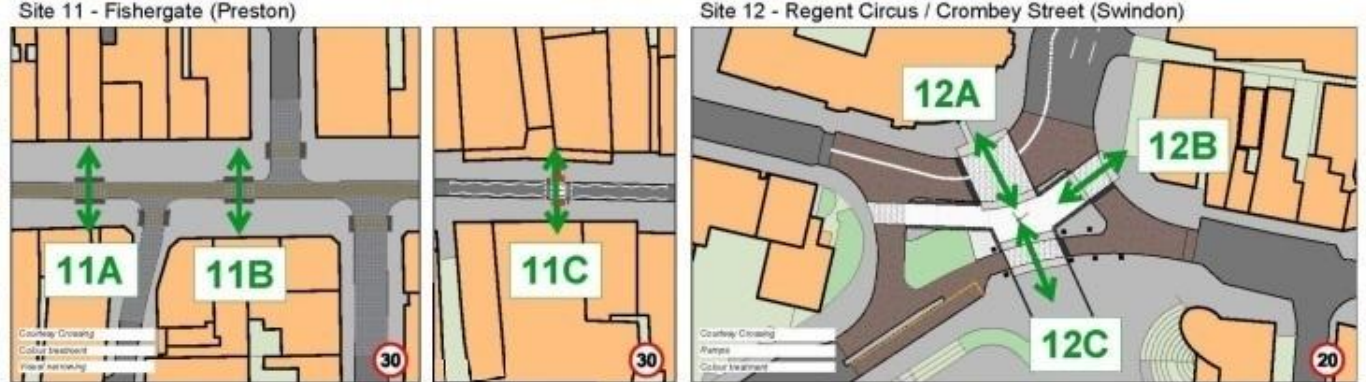